\title{
الأمن المائي في الجزائر واستراتيجية تحقيقه
}

\section{Algerian water Security and Strategy of its Realization}

\author{
تاريخ الاستلام :2020/03/04؛ تاريخ القبول: 2020/08/31
}

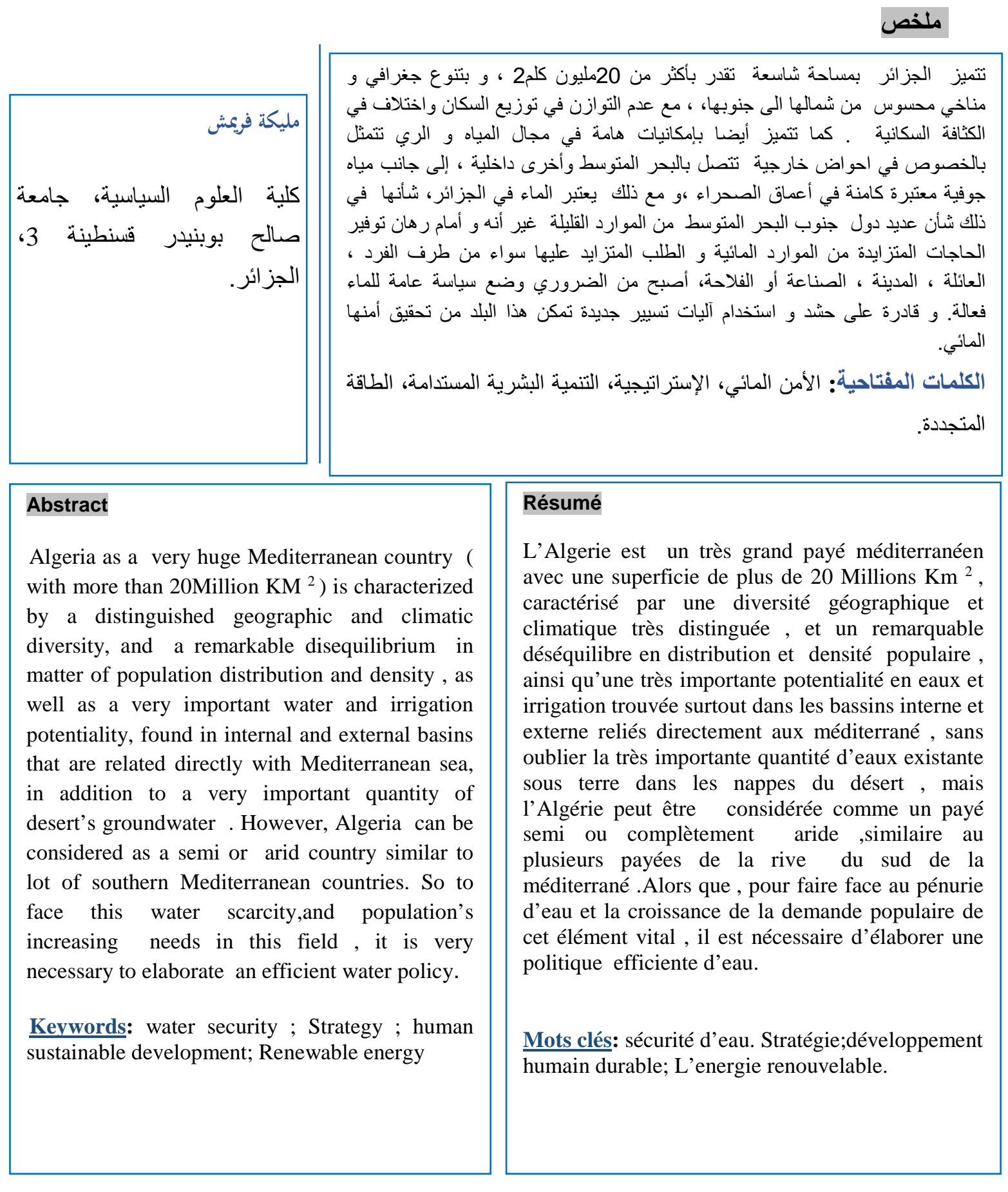

* Corresponding author, e-mail: malika.frimeche@univ-constantine3.dz 


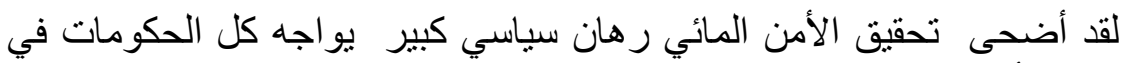

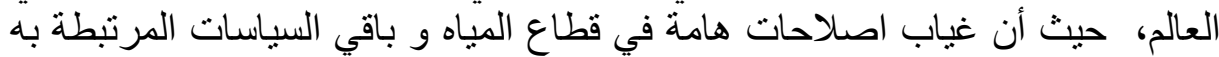

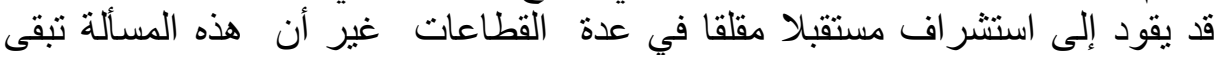

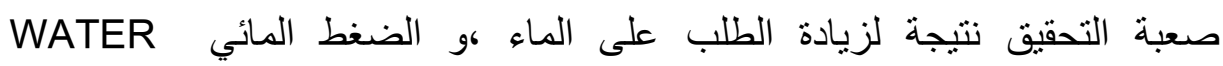
STRESS لتطوير فاعلية وفعالية إدارة المياه لبلوغ القدرة على تلى تسيير الأخطار المتعلقة بالندرة الإنه

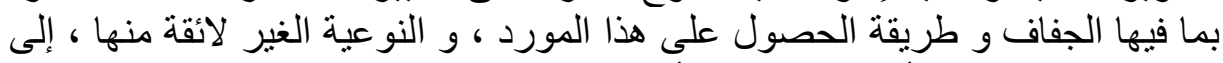

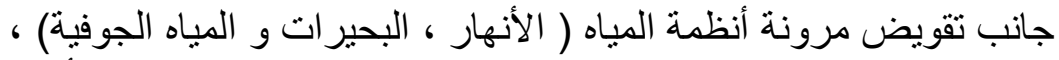

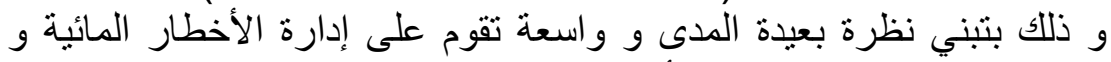

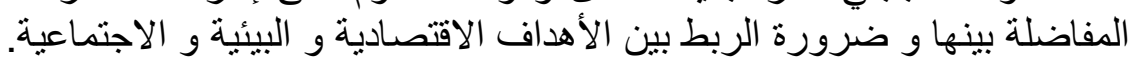

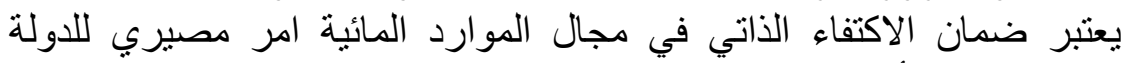

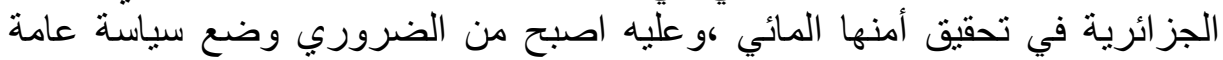

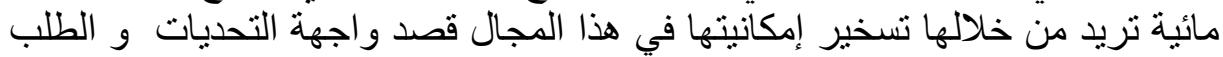

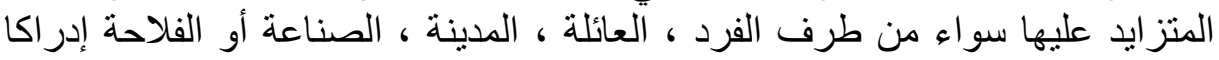

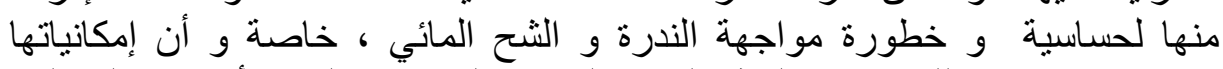

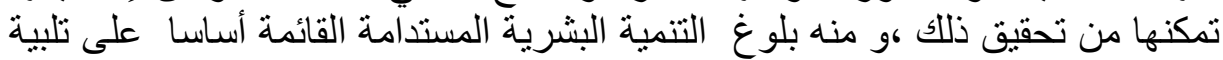
حاجيات الأجيال الحالية مع المحافظة على حق أجيال المستقبل في القيام بذلك .

\section{أولا ـ الأمن المائي بين المفهوم و الأهمية :}

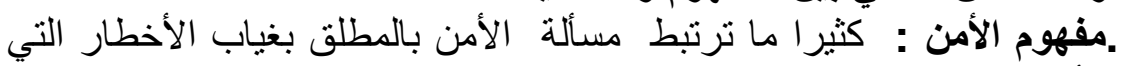

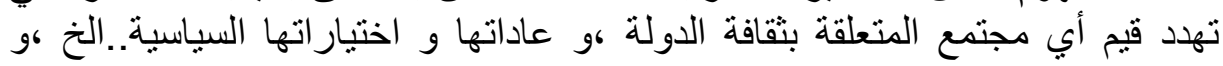

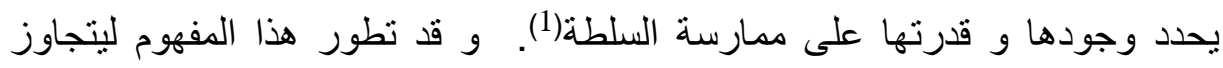

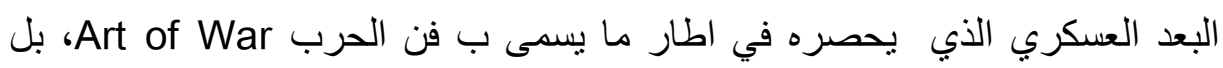

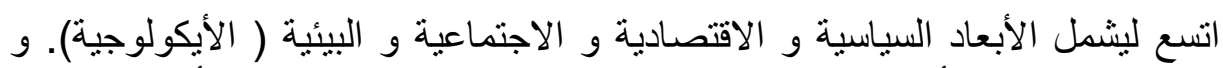

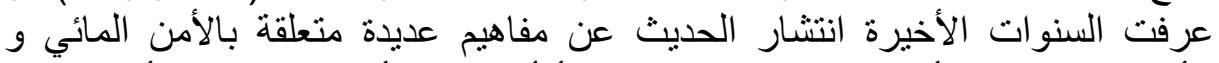

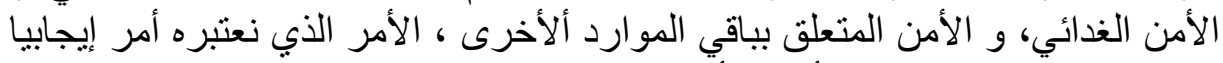

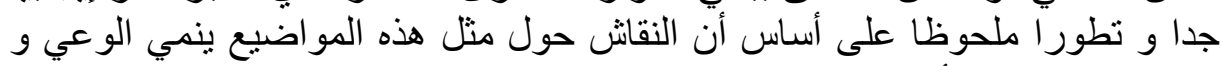

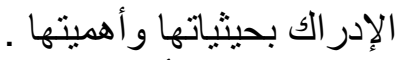

عرف الأمن المائي عل أساس قدرة الهابـ السكان على الحصول المستمر و الدائم

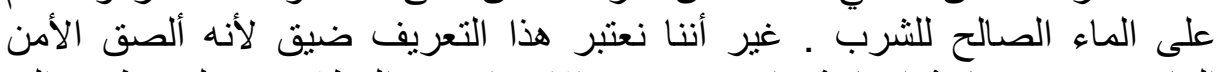

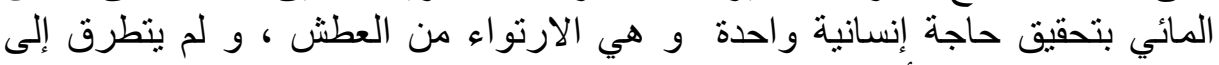

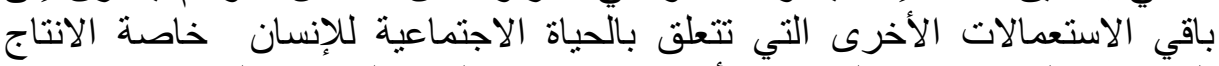

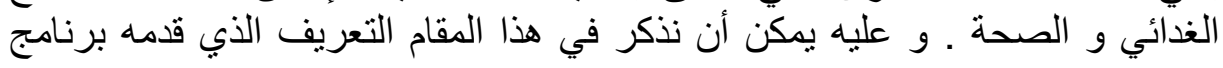

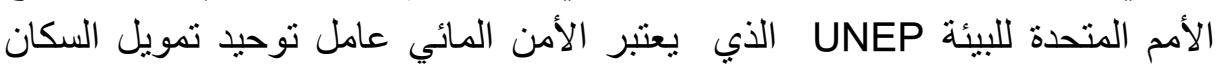

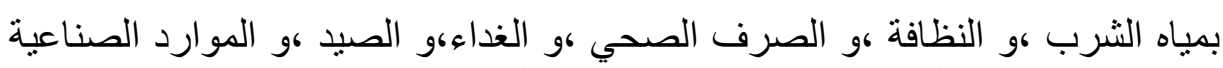

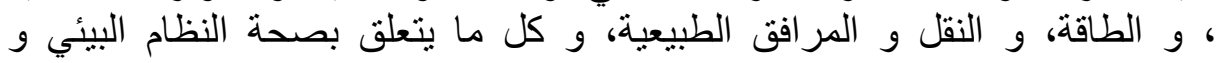

(2)"الإنتاجية

و تعرفه Wikipedia على أساس توفر لكمية و نوعية مقبولة من المياه قصد

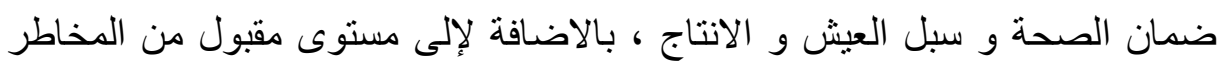


المتصلة بالماء ـ و هو مرتبط ارتباط كبيرة بتحقيق التنمية المستدامة التي لا يمكن

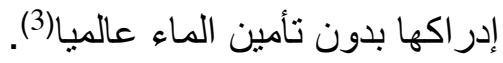

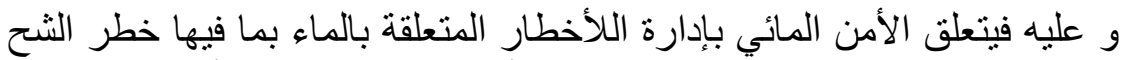

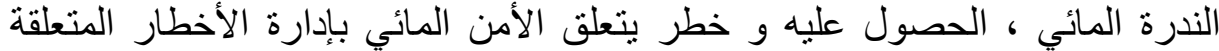

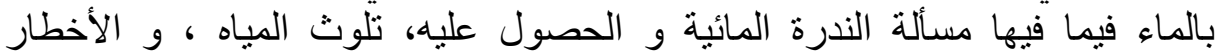

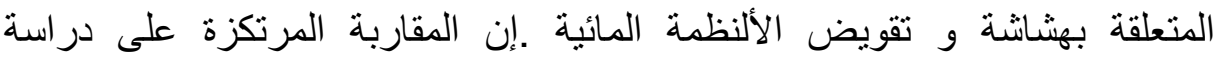

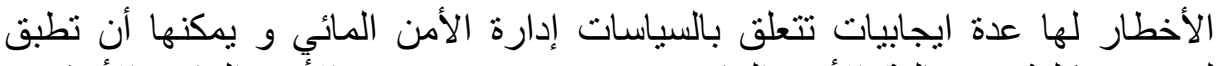

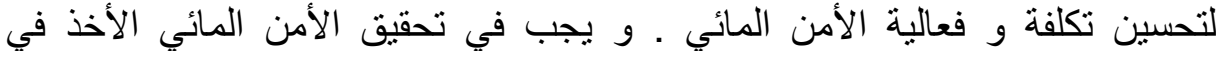

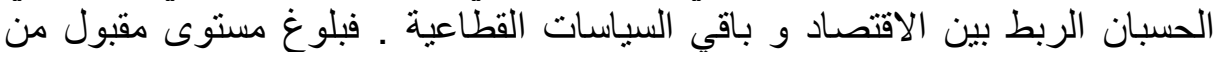
الأخطار المائية يجب أن يكون حصيلة نظام معلوماتي جيد يربط الأمن المائي بباقي أهداف السياسات القطاعية الأخرى • و يتطلب بلوغ تحقيق رهان الانسجام مقاربة متجانسة بين قطاع المياه و باقي السياسات القطاعية و البيئية(4) . الأمن المائي ضَضرورة لانتعاش القطاع الزراعي:

تشكل الزر اعة حوالي 70 \% من استهلاك المياه العذبة عالميا ، و بالتالي فهي

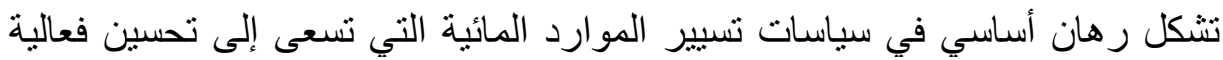
استعمال المياه و الاستجابة إلى الاحتياجات البيئية و الاجتماعية. تعد عملية تسيير التيلية فيلية

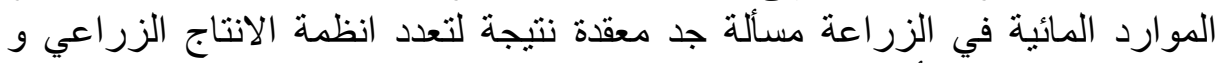

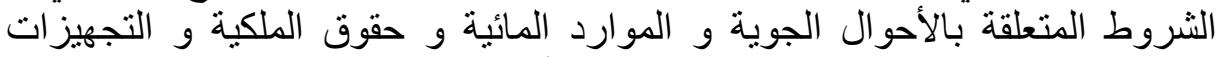

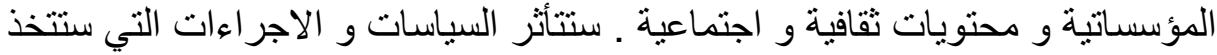

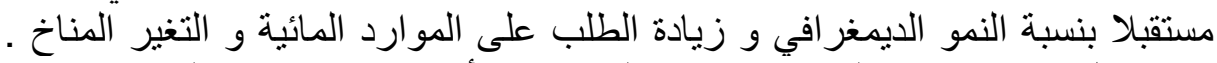

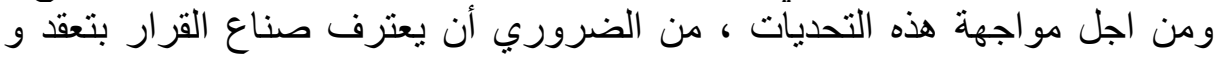
تنوع تسيير الموارد المائية في قطاع الزراعة التهاء ، اصلاح الهياكل المؤسساتية لتسيير

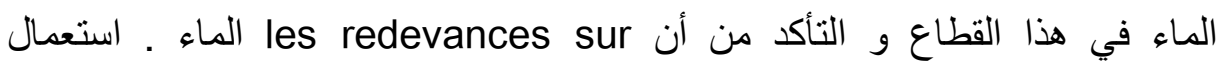

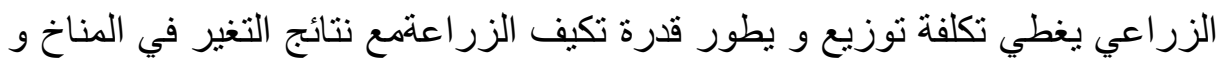

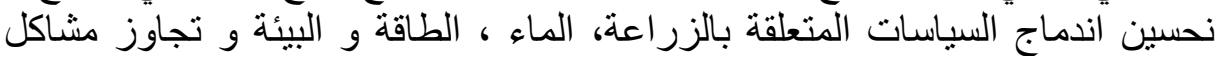

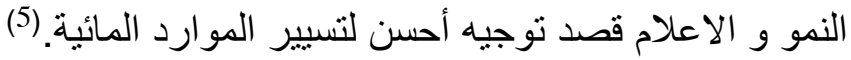

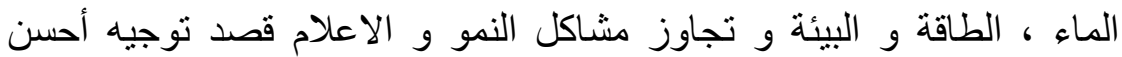

لتسيير الموارد المائية.

\section{3.تمويل المالي لخدمات المياه و التطهير :}

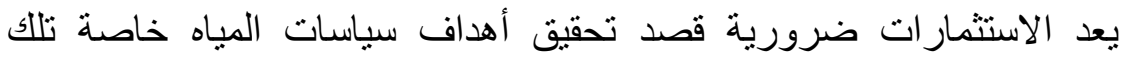

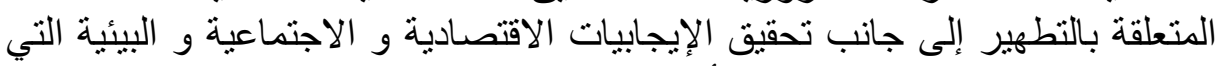

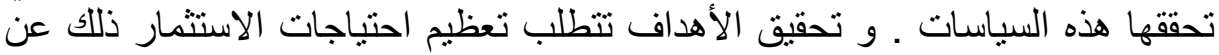

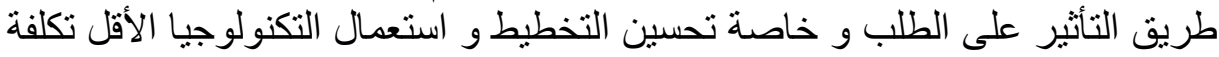

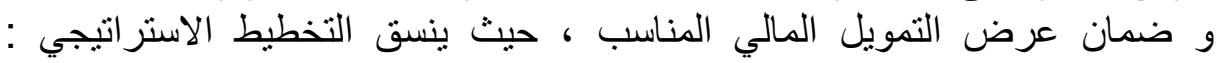

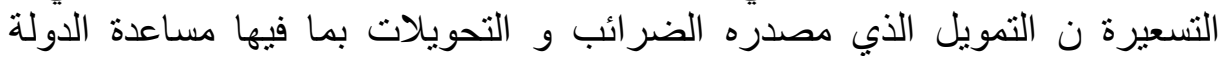
للتنمية التي لها دور هام لتحقيق الأهداف المتعلقة بالماء و التطهير (7) 


\section{ثنانيا التنمية البشرية و الأمن المائي :}

يعتبر الماء عنصر مهم في تحقيق التتمية البشرية و الاقتصادية و إلى حياة

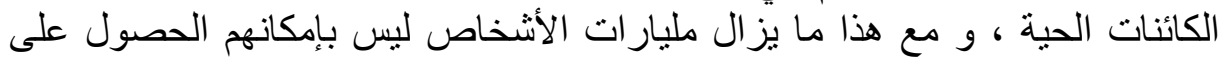

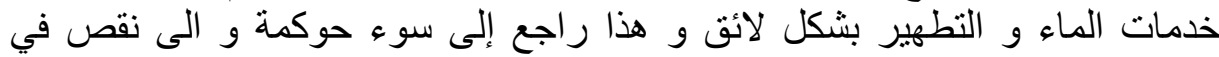

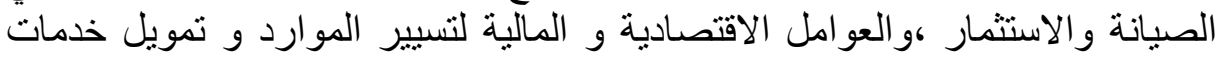

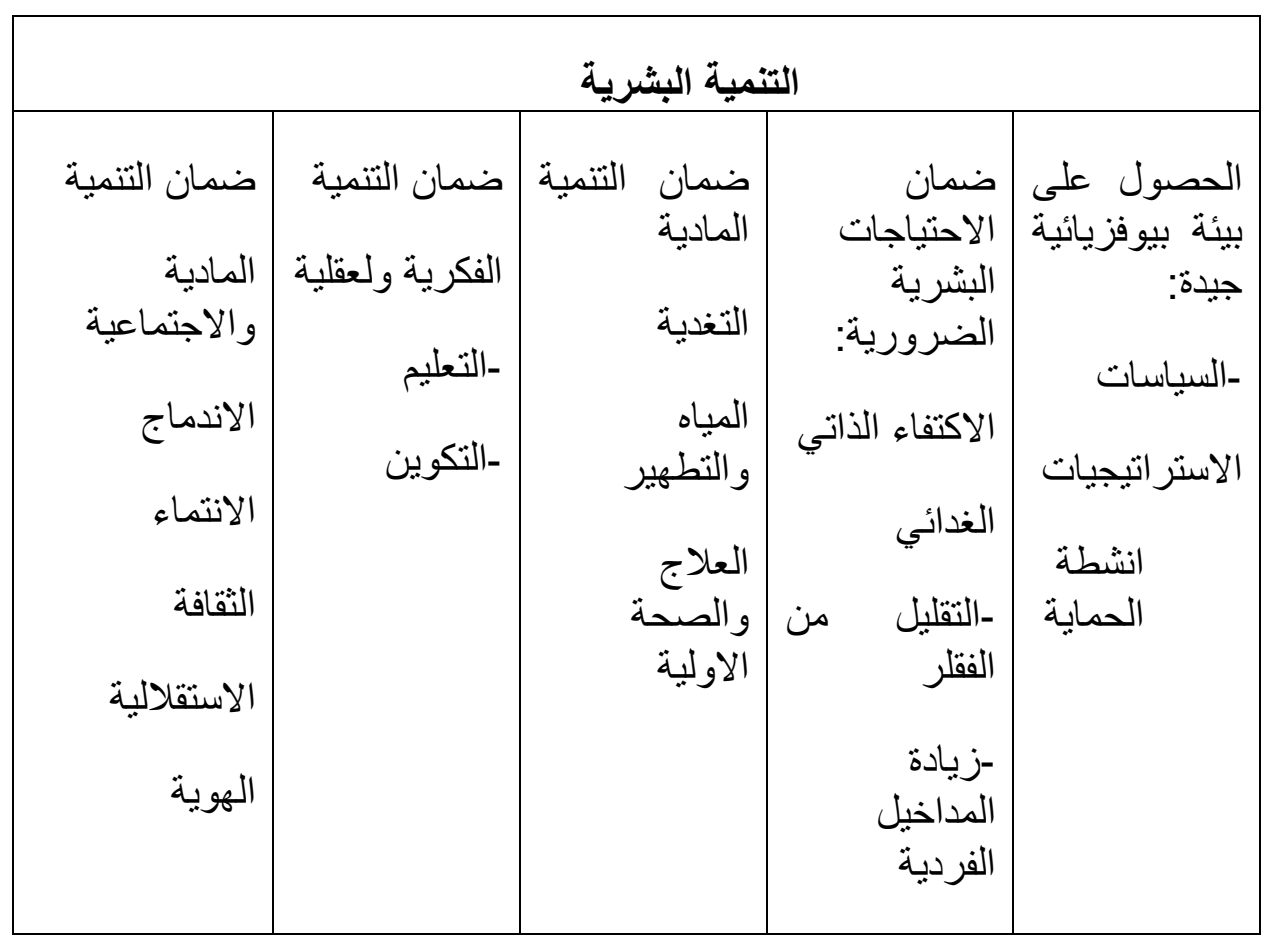

\section{ـ الموارد المائية : رهانات و تحديات الألفية:}

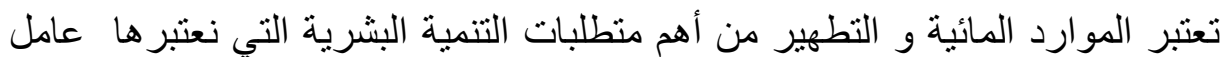

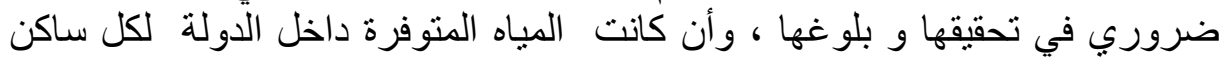

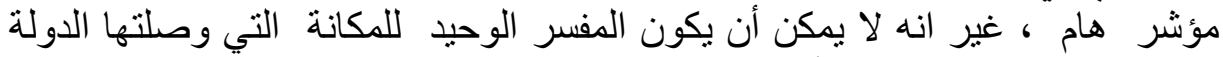

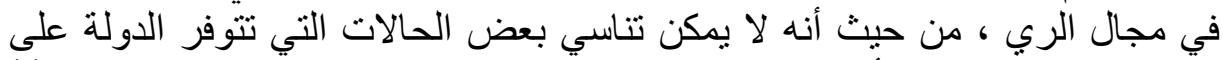

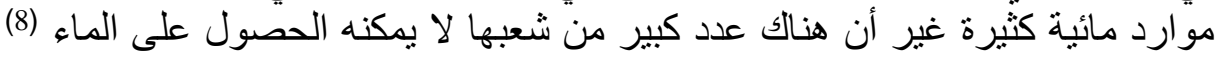

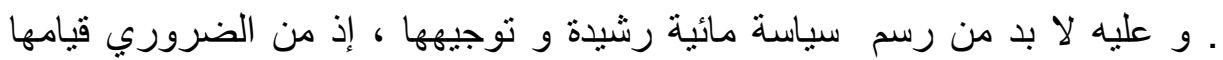

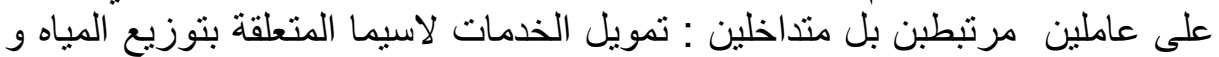

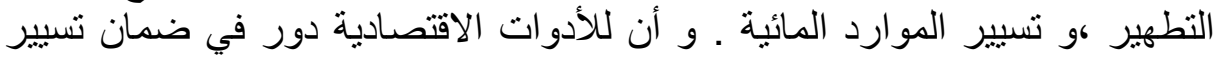

جيد للموارد المائية (9) 
الامن المائي في الجزائر واستر اتيجية تحقيقه

\begin{tabular}{|c|c|c|}
\hline المشاريع المبرمجة & الدينار انبة بمليار & القطاع \\
\hline 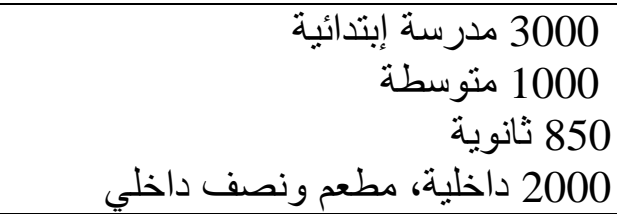 & 852 & التربية الوطنية \\
\hline 44 مطعم جامعير في إقامة جامعية بيداغوجية & 868 & التعليم العالي \\
\hline 52 مركز 5220 & 178 & التكوين المهني \\
\hline 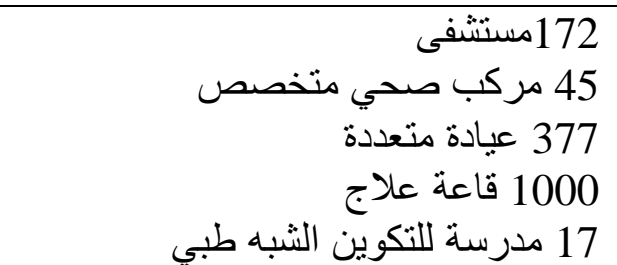 & 619 & الصحة \\
\hline 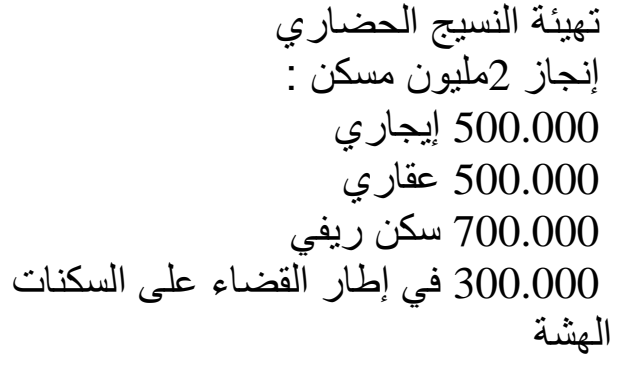 & 3700 & 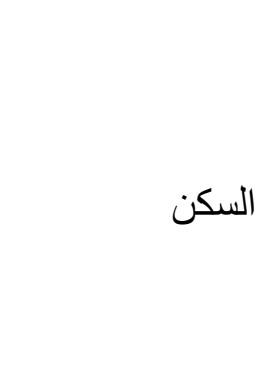 \\
\hline 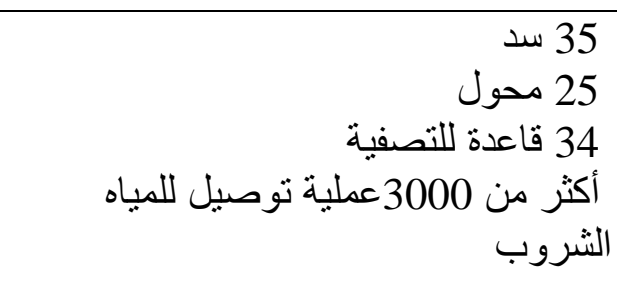 & أكثر من 2000 & 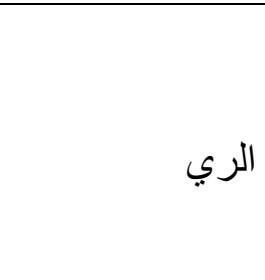 \\
\hline مليون مسكن توصل بالغاز الطبيعي 220.000 مسكن ريفي بالكهرباء & أكثر من 350 & الطاقة \\
\hline 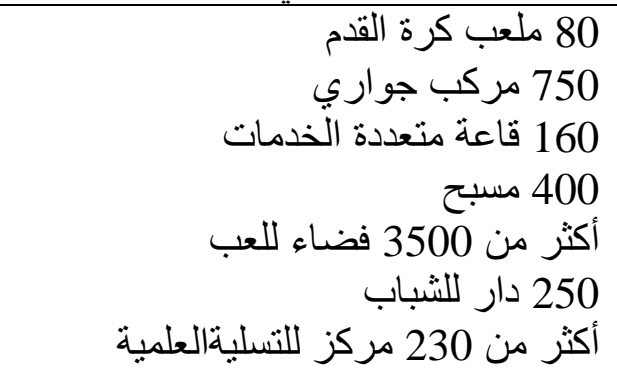 & 1130 & الثباب و الرياضة \\
\hline 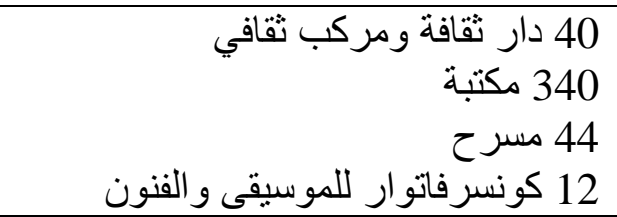 & 140 & الثقافة \\
\hline
\end{tabular}




\begin{tabular}{|c|c|c|}
\hline الجميلة 156 مركز للتسلية العلمية & & \\
\hline تطوير تجهيز ات التبر اديو والتلفزيون & 106 & الإتصالات \\
\hline 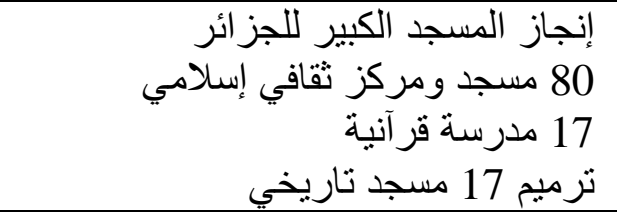 & 120 & الثؤون الدينية \\
\hline 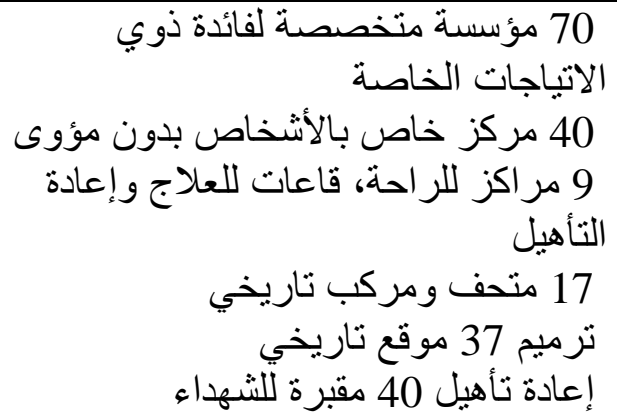 & 40 & التضامن الوطني \\
\hline
\end{tabular}

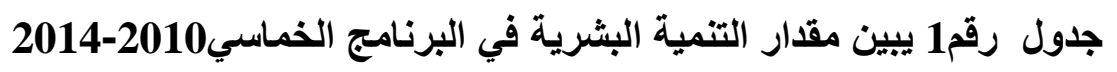
وقد خصص حوالي 27 مليار للاستثمار العمومي في قطاع المياه و النئن الري في هذه

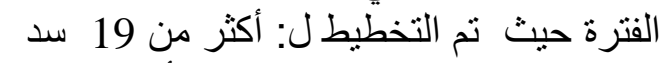
25 نظام تحويل للمياه من السدود أو المياه الجوفية 34محطة للتهيئة

40محطة للتصفية المياه المستعملة لمبنة أكثر من 3000 عملية توصيل للمياه الثروب، التطهير و حماية الددن من الفياضانات

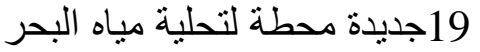
إعادة تأهيل و تحديث شبكات توصيل المياه على مستوى التراب الوطني أب ما يعادل 2 65000 تحقيق و انشاء شبكات الإمداد و التوزيع و تأهيل شبكات توصيل المياه الثروب في حو الي 32 مدينة و التطهير في حوالي 24 مدينة

\begin{tabular}{|c|c|c|c|c|}
\hline 2014 & 2010 & 2005 & 1999 & 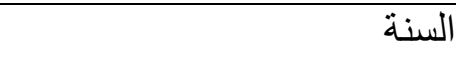 \\
\hline 1200 & 750 & 680 & 600 & حجم المباه المستعملة ب م3 \\
\hline 1100 & 665 & 160 & 90 & القدرة الوطنية للمعالجة \\
\hline 185 & 112 & 34 & 33 & محطات تصفية المياه المستعملة \\
\hline $95 \%$ & $86 \%$ & $85 \%$ & $\% 72$ & صرفبة المياه النية لنوصيل بقنوات \\
\hline
\end{tabular}

جدول2 يمثل القدرات الوطنية لتصفية المياه المستعطلة 
الامن المائي في الجزائر واستراتيجية تحقيقه

\begin{tabular}{|c|c|c|c|c|c|}
\hline $2017 / 2014$ & 2010 & 2005 & 1999 & السدود & الموارد المائية \\
\hline 93 & 66 & 56 & 47 & العدد & \\
\hline 9.1 & 7.1 & 5.7 & 4.2 & قدرة الاستيعاب & \\
\hline
\end{tabular}

جدول3 يمثل الموارد المائية السطحية

\begin{tabular}{|c|c|c|c|c|}
\hline 2014 & 2010 & 2005 & 1999 & السنة \\
\hline 3.6 & 2.9 & 1.7 & 1.25 & 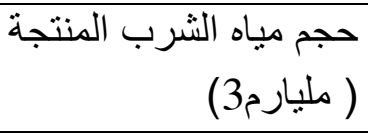 \\
\hline 175 & 170 & 155 & 123 & ساكن باللتر اليومي /لكل \\
\hline $98 \%$ & $93 \%$ & $89 \%$ & $78 \%$ & نسبة ربط الثبكات \\
\hline
\end{tabular}

بدأت الأفكار الأساسية لسياسة الماء في الجزائر تظهر ابتداء من الجلسات الوطنية حول المياه التي انعقدت في جانفي 1995 و التي قامت على مبادئها الخمس الجديدة و

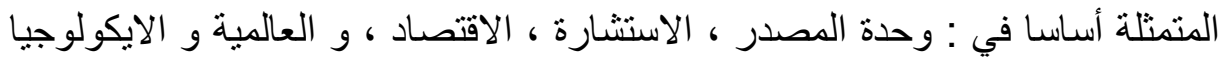

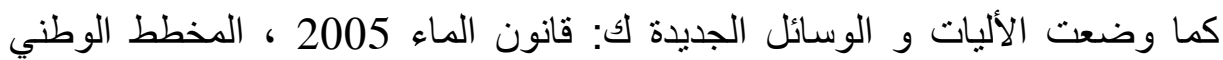

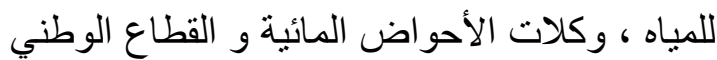

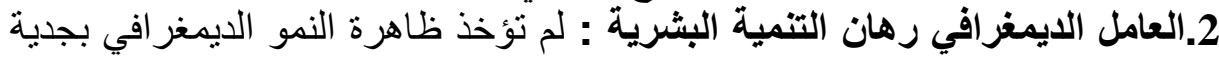

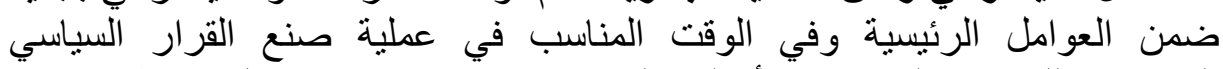

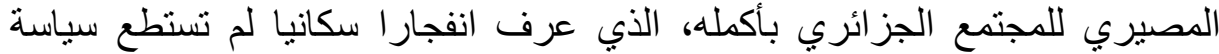

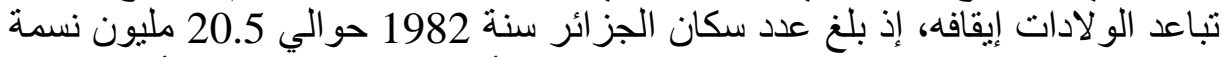

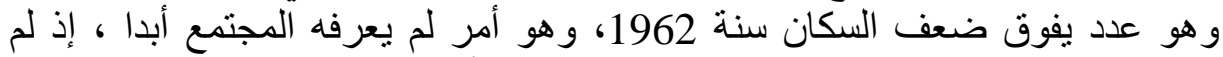

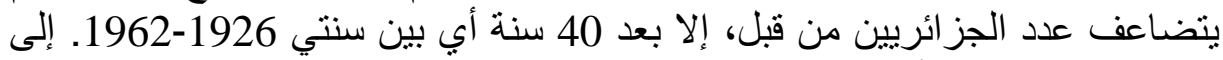

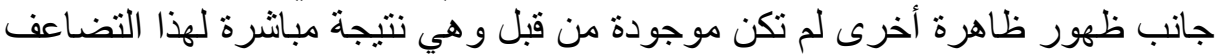

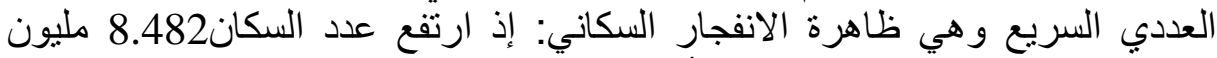

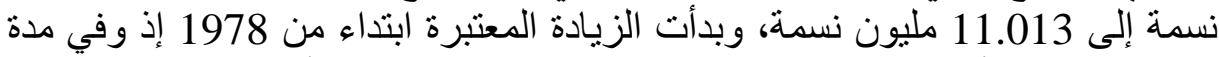

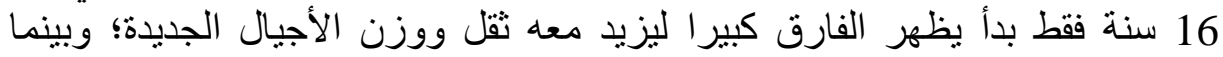

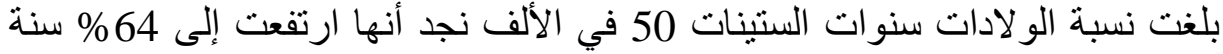

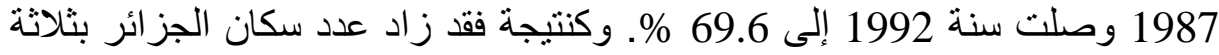

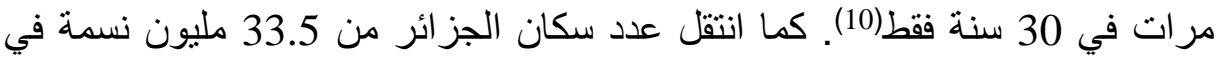
جويلية 2006 إلى 33.8 مليون نسمة في جانفي 2007 ليرتفع إلى 34.4 مليون نسمة

في جانفي 2008. (11)

\begin{tabular}{|c|c|c|c|}
\hline نسبة النمو\% & نسبة الوفيات \% & نسبة المواليد\%\% & السنة \\
\hline 2.49 & 6.03 & 30.94 & 1990 \\
\hline 2.41 & 2.04 & 30.14 & 1991 \\
\hline 2.43 & 6.09 & 30.41 & 1992 \\
\hline 2.25 & 2.26 & 28.22 & 1993 \\
\hline 2.16 & 6.56 & 28.24 & 1994 \\
\hline
\end{tabular}




\begin{tabular}{|r|r|r|r|}
\hline 1.89 & 6.43 & 25.33 & 1995 \\
\hline 1.68 & 6.03 & 22.91 & 1996 \\
\hline 1.63 & 6.12 & 22.51 & 1997 \\
\hline 1.57 & 6.87 & 20.52 & 1998 \\
\hline 1.51 & 4.72 & 19.82 & 1999 \\
\hline 1.48 & 4.59 & 19.36 & 2000 \\
\hline 1.55 & 4.56 & 20.03 & 2001 \\
\hline 1.53 & 4.41 & 19.68 & 2002 \\
\hline 1.58 & 4.55 & 20.36 & 2003 \\
\hline 1.63 & 4.36 & 20.67 & 2004 \\
\hline 1.96 & 4.74 & 21.30 & 2005 \\
\hline 1.76 & 4.30 & 22.07 & 2006 \\
\hline
\end{tabular}

جدول رقم4: يمثل تطور نسبة النمو السكاني في الجزائر(12)

و عليه فقد كان من الضروري عدم تجاهل نتائج هذا العامل المهم أثناء وضع السياسات و الاستر اتيجيات التنموية المستقبلية تلية

ثالثا :السباسة المائية في الجزائر :

1.البداية المحتشمة :

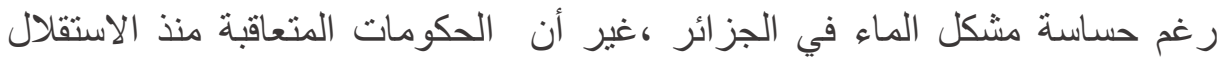

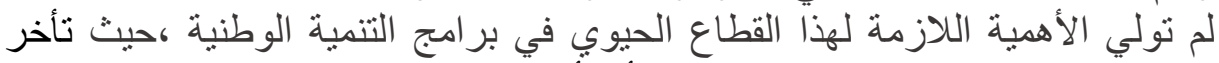

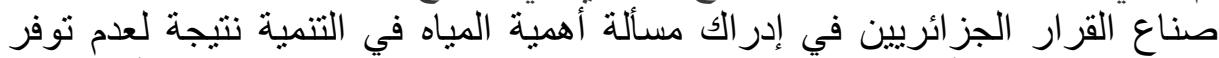

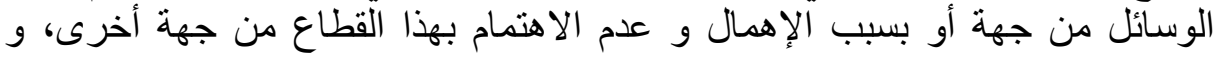
استمر هذا الوضع إلى غاية سنوات 1990 أين كان مخزون المياه قليل جدا إلى درجة الإنة

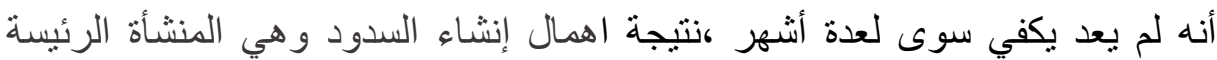

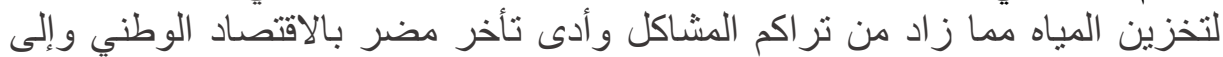

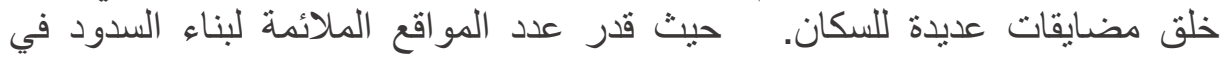
الجزائر من الناحية النظرية بنحو250 موقعا، لكن عدد السدود المنجزة لغاية عام

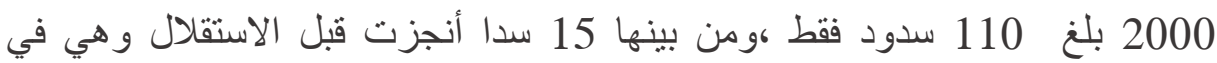
معظمها من السدود الصغيرة والمتوسطة ومنها 50 سدا كبير بطاقة تفوق10 ملايين م3, يبلغ حجم تخزينها الإجمالي و حسب دراسة لمركز تطوير الطاقات المتجددة أنجزت سنة 1964،فقد تم انجاز ثلاث وحدات بسعة 8 م3 في اليوم لكل واحدة في مركب الغاز المميع أرزيو ليتم

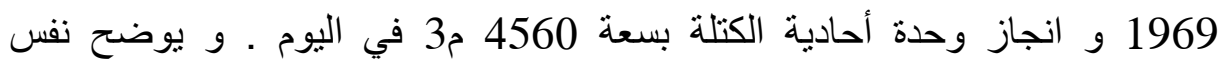

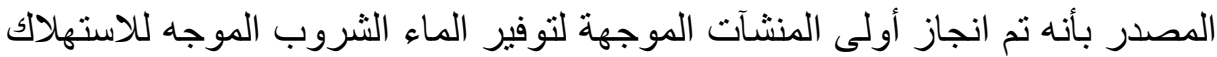

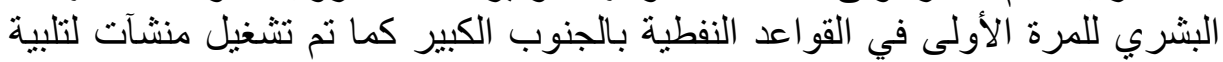

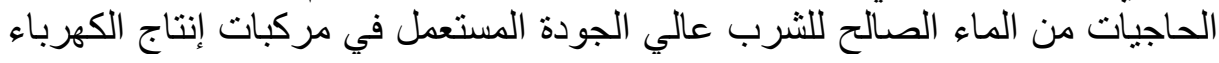

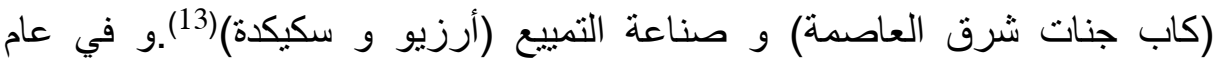


1980 تم تدشين وحدة تحلية مياه البحر على طريقة الأوسموس (الأثر المتبادل) بسعة 57600 م3 في اليوم والتي صنفت حينها كأهم وحدة في العالم.ويقدر الخبراء عدد المواقع الملائمة لبناء السدود في الجزائر من الناحية النظرية بنحو 250 موقعا ، لكن عدد السدود الصغيرة والمتوسطة ومنها 50 سدا كبير بطاقة تخزين تفوق 10ملايين م3 . يبلغ حجم تخزينها الإجمالي 4.908 مليار، لكن منوسط حجم المخزون المنوفر في العشر سنوات الاخيرة قدر بنحو 1.75 مليار م3 ، فقط ما يعادل 40\% من طاقة التعبئة الاجمالية النظرية بسبب الظروف المناخية ( الجفاف ) ومشكل توحل السدود . 2.الامكانيات المائية في الجزائر:

تحتوي الجزائر على مصدرين هامين :الأول خاص بالمياه العذبة و نقصد به خاصة غالة la nappe Albienne

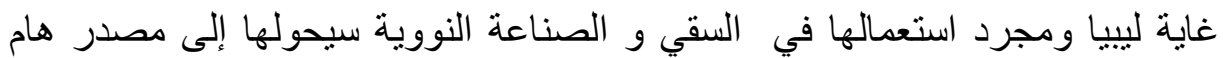

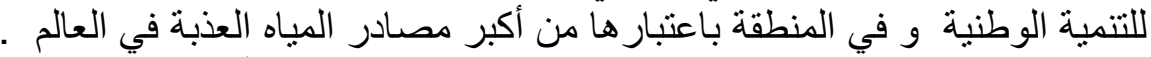

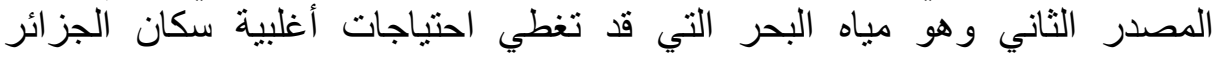
المتمركزين في المنطقة الساحلية : حيث أدركت الجزائر مند سنوات 1990 أن أن عليها

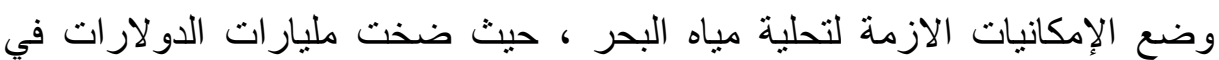

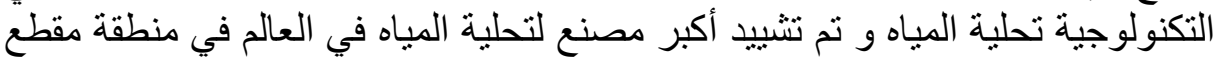
في و هران الذي كلف الدولة حوالي 492 مليون دولار و بقدرة انتاجية

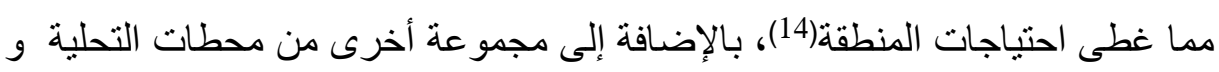
التي يستضاف لها 33 محطة إلى غاية 2019

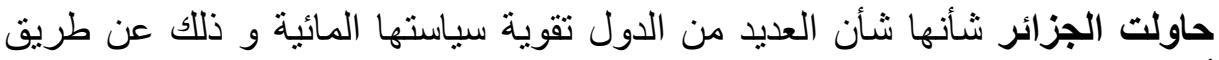

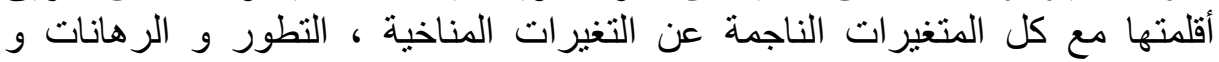

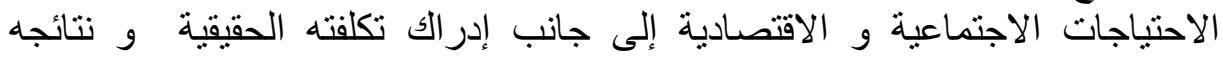
الاقتصادية. و ابتداء من 1996 تبنت الجزائر سياسة مائية جديدة قائمة على التسيير الملتزم

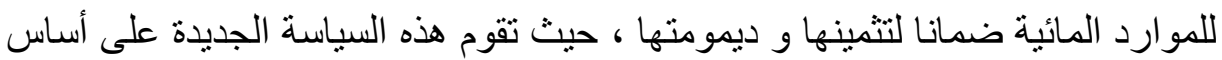

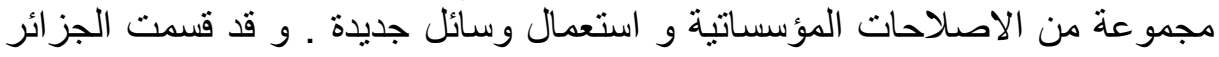
إلى 05 أحواض كبرى و أنثأت داخل كل حوض هيئات و المتمثلة أساسا في وكلات

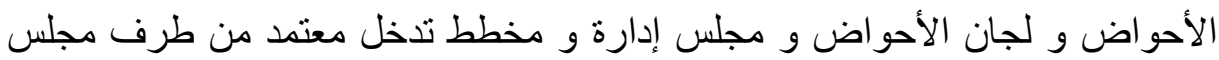

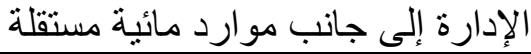

\begin{tabular}{|c|c|c|c|}
\hline الموارد & المياه الجوفية & السطياه & $\begin{array}{l}\text { المناطق الهيدروغر افية } \\
\text { hydrographique }\end{array}$ \\
\hline 1.6 مليار م3 & 0.6 مليار م3 & 1 مليار م3 & منطقة و هر ان - شط شرقي \\
\hline 1.83 مليار & 33.30.3 مليار م3 & 1.5 مليار & شلف-ز هراز \\
\hline م3 & & r & \\
\hline - 4.14 مليار & 0.74 مليار & 3.4 مليار & الجز ائر _الحظنى_الصومام \\
\hline م3 & ק3 & م3 & \\
\hline
\end{tabular}




\begin{tabular}{|c|c|c|c|}
\hline م3 4.43 مليار & م3 0.43 مليار & 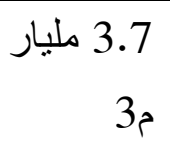 & قسنطينة-سيبوس- ملاق \\
\hline $\begin{array}{l}\text { La nappe } \\
\text { albienne }\end{array}$ & 5 مليار م3 & م3 0.2 مليار & الصحر اء \\
\hline
\end{tabular}

ضرورة الحفاظ على هذه الموارد الثمينة لكونها أحفورية أي غير متجددة. و عليه، فإن

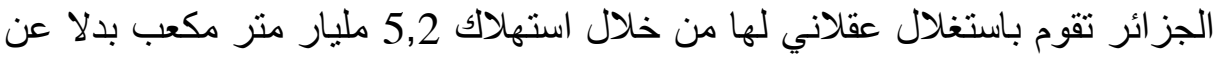
5 ملايير متر مكعب سنويا لضمان الإبقاء عليها. أن طاقة استخراج الموارد المائية تصل إلى ملياري منر مكعب في الثمال وحوالي 2,2 مليار منر مكعب في الجنوب. ونظرا لطبيعة المناخ الجاف، فإن المخزون المائي الجوفي يتم استغلاله بصورة متدرّجة وعقلانية لضمان عدم استنزافه وترك المُ المجال لتجديده على مدى زمني معلوم. و تؤكد التصريحات الرسمية أن حصة الجزائري من المياه الصالحة للشرب تقدّر

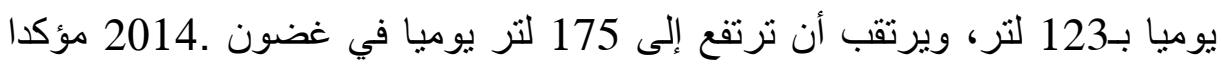

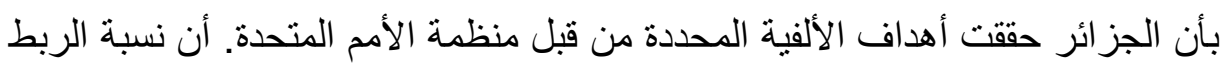

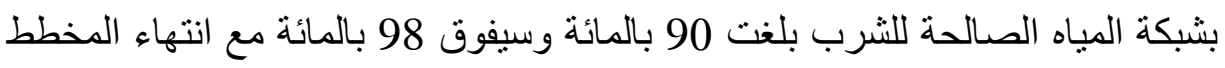
الخماسي .2010/2014 بالمقابل تقدر نسبة الربط بشبكة التطهير 87 بالمائة وينتظر أن تصل 95 بالمائة في غضون 2014 أيضا(15).

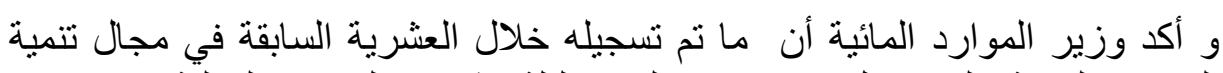

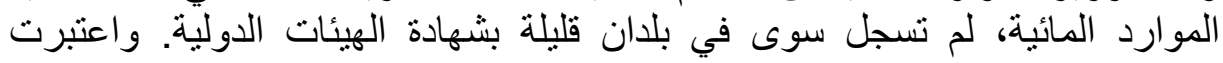

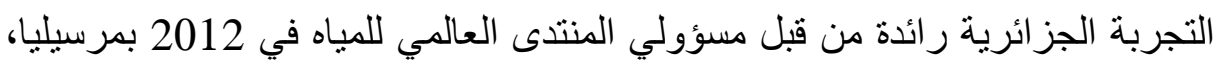

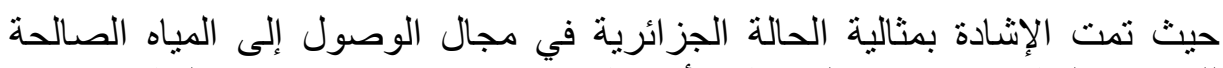

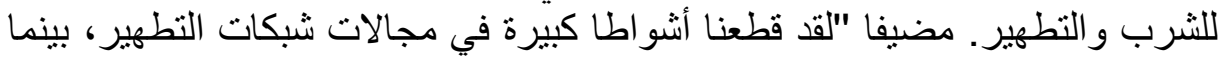

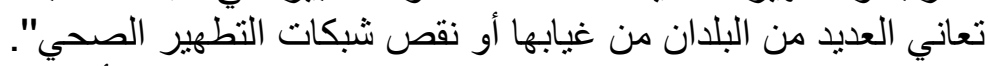

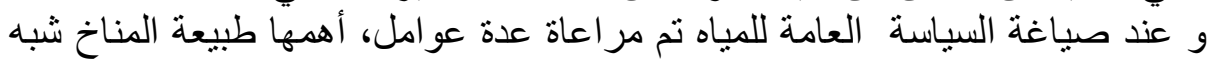

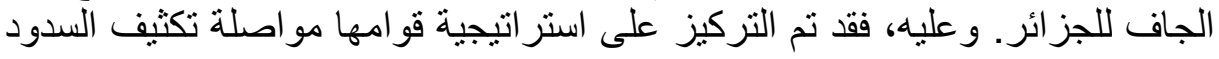
التي سيصل عددها إلى 84 سدا في غضون 2014 واستغلال عقلاني و وعلمي للمياه الجوفية وعدم الاكتفاء بتساقط المياه وتطوير الموارد المائية غير التقليدية، من خلان فيلال

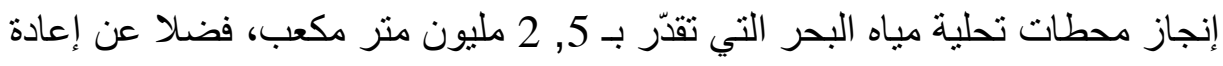

استغلال المياه المستعملة بعد معالجتها لاستخدامها في سقي الأر اضي الفي الفلاحية

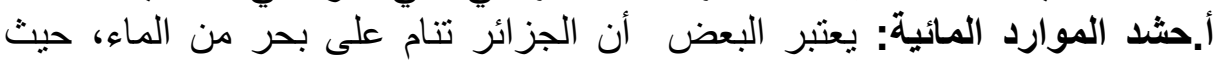

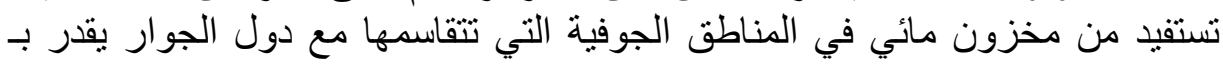

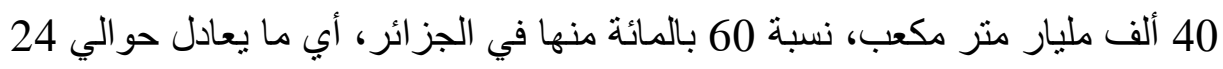
ألف مليار متر مكعب.

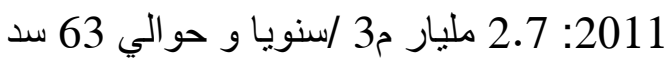

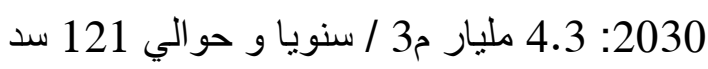


تطوير عملية اعادة استعمال المياه المستعملة بقدرة حوالي 1.2 مليار م3 / سنويا حوالي 2015

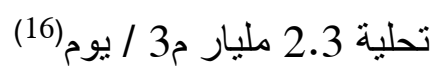

ب.مبادئ السياسية المائية : لقد بدأت الأفكار الأساسية لسياسة الماء في الجزائر

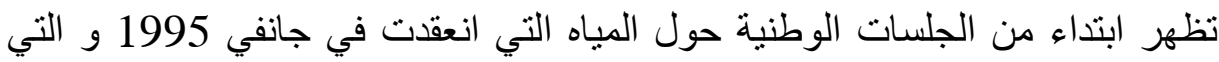

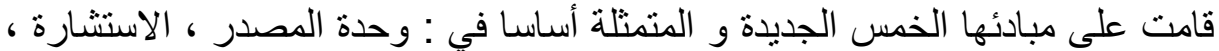

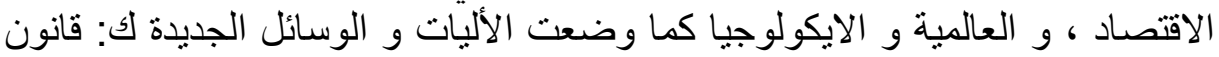

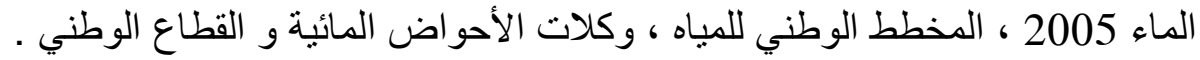
وتقوم السياسة المائية في الجزائر على مجموعة من المبادئ التي نعتبر ها مهمة جدا

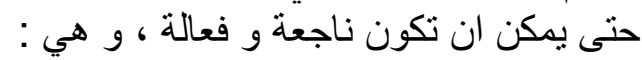

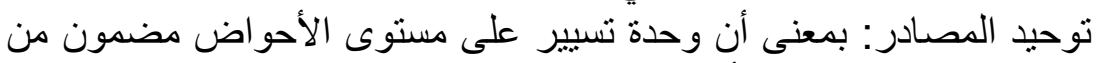
طرف وكلات و كلات الأحو اض وحند ؛

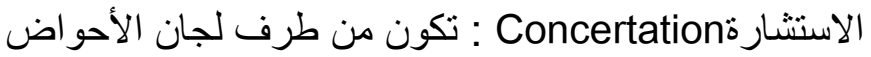

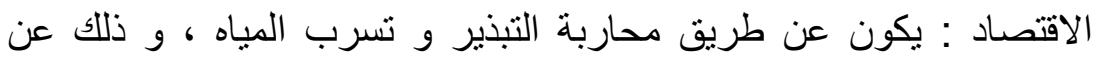
طريق إعادة تأهيل شبكات و تحسيس المستعملين • البيئة : لأن الماء هو مورد ناذر و هو هو مشترك للجميع يجب حمايته من كل

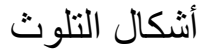

\begin{tabular}{|c|c|c|}
\hline حجم التخزين مليون م3 & بداية الاستخلال مسل & اسم السد إن \\
\hline 200 & 1963 & أر اقن ( جيجل) \\
\hline 15 & 1963 & مفروش ( تلمسان ) \\
\hline 170 & 1965 & شفيعة ( الطارف) \\
\hline 355 & 1969 & جرف التزبة بشار \\
\hline 18 & 1970 & فرقوق( معسكر) \\
\hline 50 & 1983 & المرجة (غليزان) \\
\hline 115 & 1985 & الدر دار( عين الدفلى ) \\
\hline 25 & 1986 & بور ومي ( البليدة) \\
\hline 101 & & ويزرت ( معسكر) \\
\hline 26 & 1986 & لكحل ( البويرة) \\
\hline 110 & 1988 & بني عمران \\
\hline 122 & 1984 & قنيطرة ( سكيكدة) \\
\hline 110 & 1985 & سلى شلف \\
\hline 50 & 1985 & عين ز ادة \\
\hline
\end{tabular}




\begin{tabular}{|c|c|c|}
\hline 09 & 1987 & الدهموني ( تيارت) \\
\hline 16 & 1987 & حمام قروز ( قسنطينة) \\
\hline 55 & 1987 & شلالة ( قالمة) \\
\hline 45 & & عين دالية ( سوق أ.) \\
\hline 92 & 1987 & قدارة ( بومرداس) \\
\hline 960 & 2004-1988 & سد بني هارون ميلة \\
\hline 110 & 1988 & بني عمران بومرداس \\
\hline
\end{tabular}

جدول رقم : يمثل أهم السدود الجزائر:

و يتوقع أن يصل عدد سدود الجزائر إلى غاية 2016 حوالي 96 سد بقدرة استيعاب

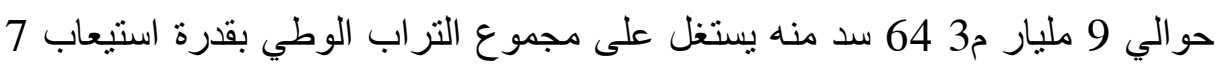
مليار م3 مقابل 44 سد سنة 1999 و قدرة استيعاب 3.3 مليار م3 ـ ـ

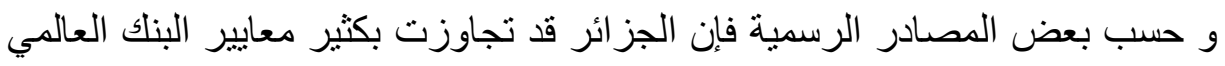

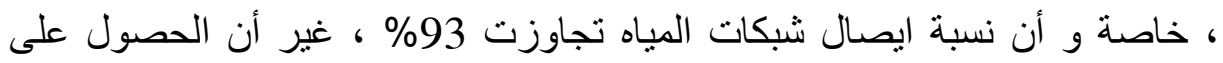

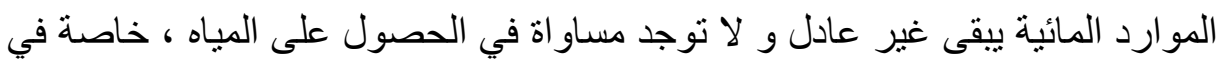

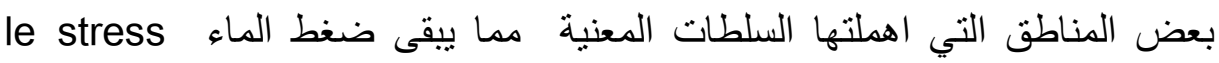
hydrique

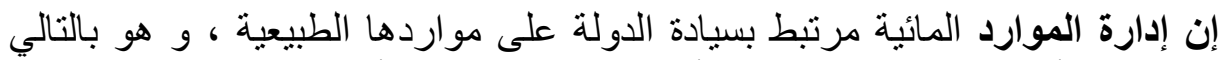

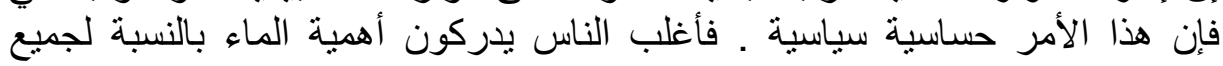

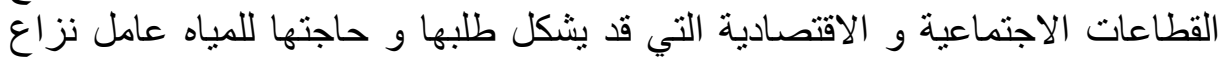

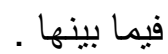
يمكن لإدارة الموارد المائية أن تكون عامل تعاون بذل أم تكون عامل نزاع و و قد بينت

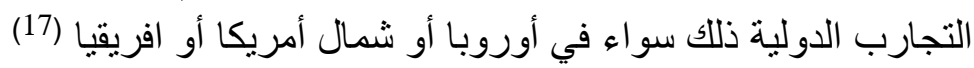

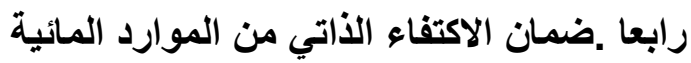

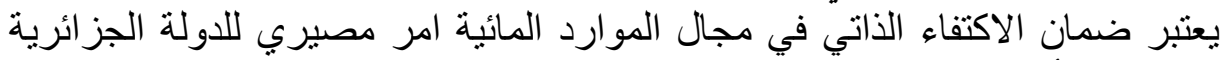

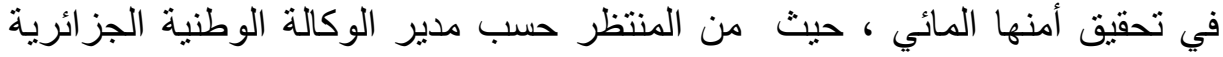

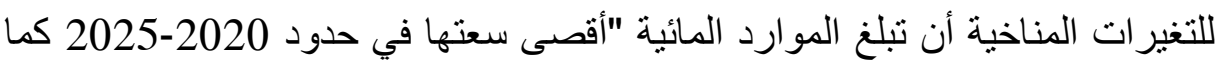

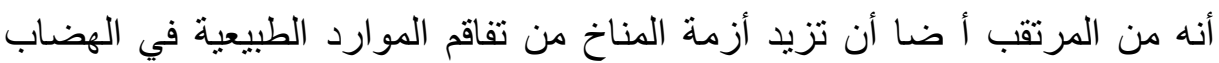

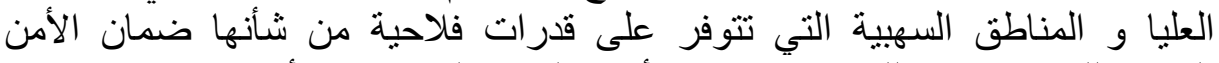

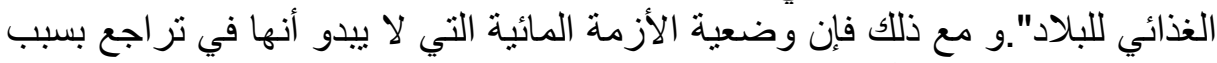

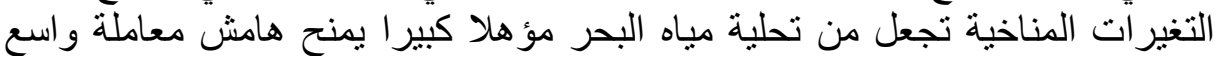

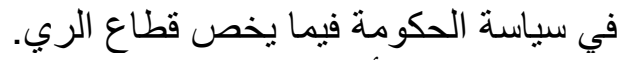

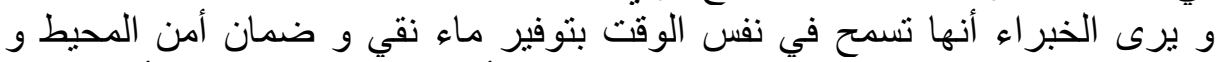

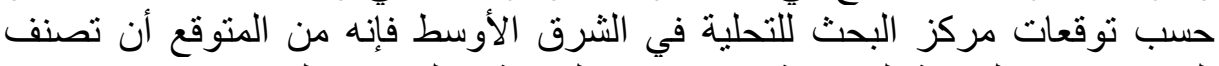

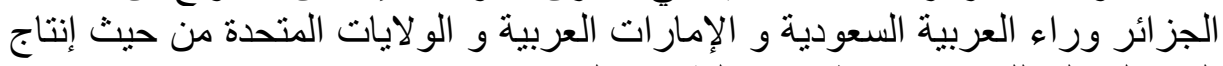
الماء الصالح للثرب عن طريق تحلية مياه البحر. 


\section{1.تحلية ماء البحر حل لندرة الماء}

مع نسبة تساقط الأمطار غير المنتظمة و التي تتراوح فقط ما بين 100 و 60 مم

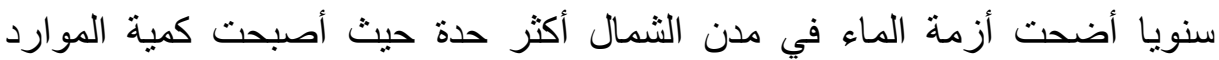

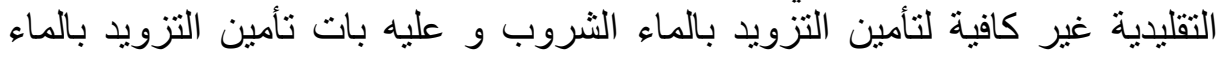

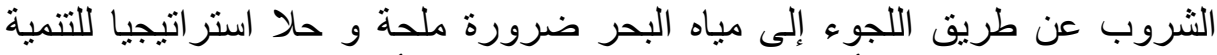

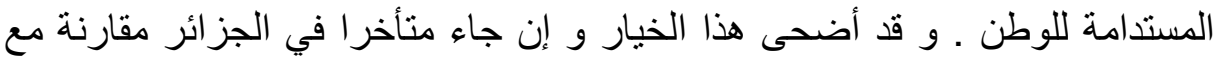

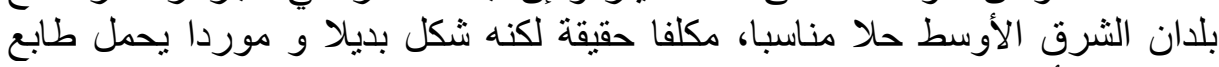

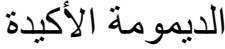

و و عليه قررت السلطات العمومية منذ حلول سنة 2001 وضع التزويد بالماء

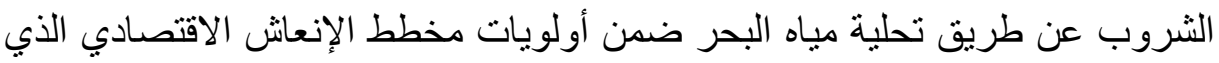
رصد له غلافا ماليا يقدر ب7 ملايير دولار لاسيما في اتجاه وهران و الولايات المجاورة التي تعاني من عجز كبير و يشنمل البرنامج الوطني على إنجاز 43 محطة تحلية مع آفاق 2019. و يتضمن هذا المخطط المفصل الذي أطلق سنة 2005 نحو 30 محطة أحادية الكتلة و 13 محطة ذات سعة كبيرة في شمال البلاد قصد إنتاج 26ر2 مليون م3 في اليوم من المياه المحلاة في حدود سنة 2019 و بتكلفة 5ر 0 دولار للمتر المربع بحيث يكون

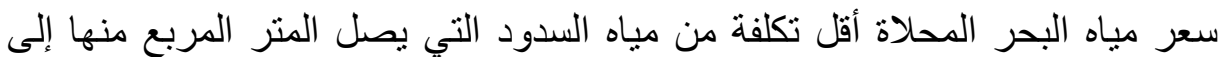
نحو 100 دج(18)و على الصعيد التقني انضمت سوناطر الك و سونلغاز اللتان تعدان أهم شركتين طاقويتين في الجزائر شهر ماي 2001 لمشروع إنشاء الثركة الجزائرية للطاقة و التي يتمثل نشاطها في تحلية مياه البحر بالثراكة مع المستثمرين الدوليين

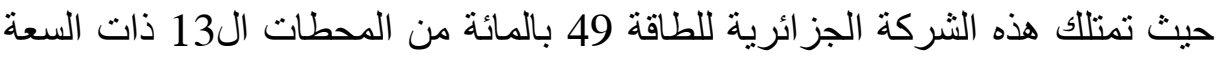

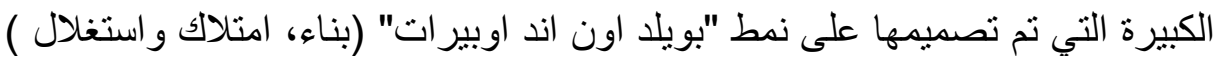
فيما يملك المستتمر الذي يستغل هذا المصنع خلال 25 سنة نسبة 51 بالمائة كما سيتم تمويلها بنسبة 30 بالمائة بالاعم في رأس المال و 70 بالمائة بتمويل محلي بهدف إنتاج 825 مليون م3 في اليوم. و من بين هذه المحطات ال13 التي برمج انجاز ها في إطار برنامج الدولة تم تشغيل ثماني منها و هي محطة كهرماء بو هران سنة 2005 (90.000 م3/اليوم) و بوسفر سنة 200512.480 م3/اليوم) و الحامة بالجزائر العاصمة سنة 2008 (200.000 م3/اليوم) و سكيكدة في بداية 2009 (100.000 م3/اليوم) و بني صاف بعين تيموشنت سنة 2010 (200.000 م3/اليوم) و سوق الثلاثاء بتلمسان في بداية 2011 (200.000 م3/اليوم) و فوكة بتيبازة في نهاية 2011 (120.000 م3/اليوم و مستغانم في بداية 2012 (200.000 م3/اليوم)(19). 


\begin{tabular}{|c|c|c|c|c|c|}
\hline \multirow{2}{*}{ الأكبرى قيدات } & \multicolumn{3}{|c|}{ المحطات المشغلة في 2010} & \multirow[t]{2}{*}{ المحطات } & \multirow{5}{*}{ تلحلية مياه } \\
\hline & المجموع & 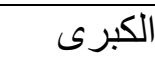 & الصغرى & & \\
\hline 9 & 25 & 4 & 21 & 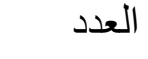 & \\
\hline 1720000 & 647500 & 590000 & 57500 & م3/ القدرة & \\
\hline 555 & 236 & 215 & 21 & $\begin{array}{l}\text { الانتاج } \\
\text { HM3 }\end{array}$ & \\
\hline
\end{tabular}

\section{2.تحويل المياه عين صالح تمنرست :}

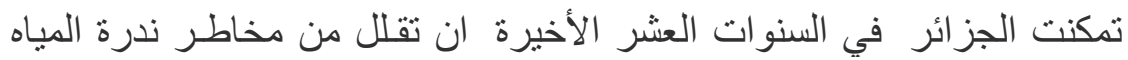

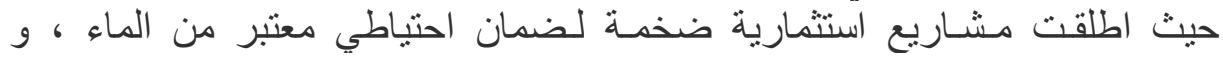

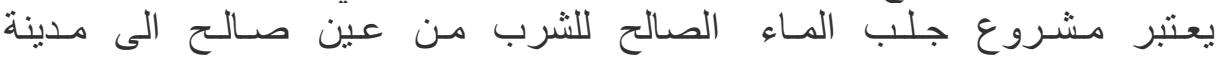
تمنر است اكبر انجـاز على مستوى قطاع الــوارد المائية بالجز ائر منذ الاستقلال

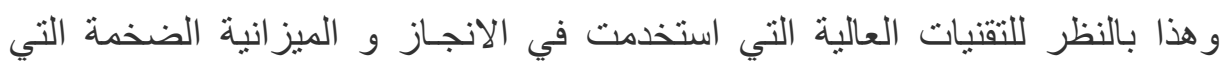

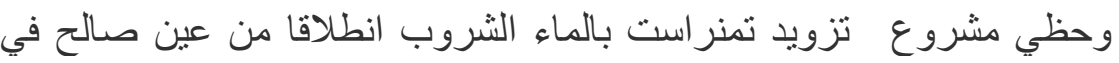

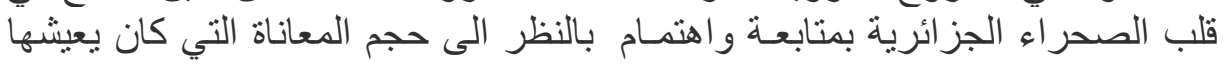

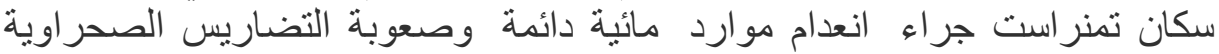

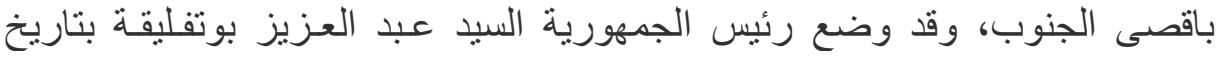
السابع من جانفي 2008 حجر اساس المشروع ليتم تدشينه في افريل 2011 ، و و قـدرت الـميز انية التي رصست لإنجـاز هذا المشروع بـ 197 مـليار دينار. و يمـتد طول المششروع على مسافـة 750 كلـم اي مـا يسـاوي 1312

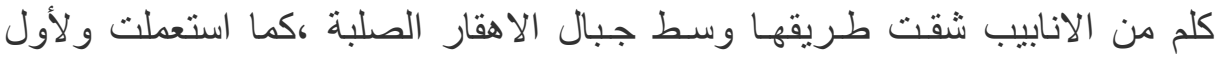

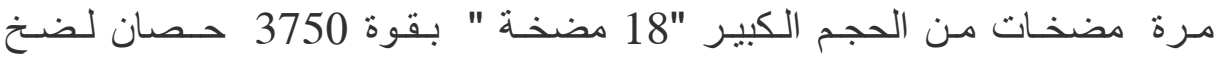
الــيـاه مـن عمى 600 م الى ارتفاع 1121 م وهي تقنية غير مسبوقـة عالميا

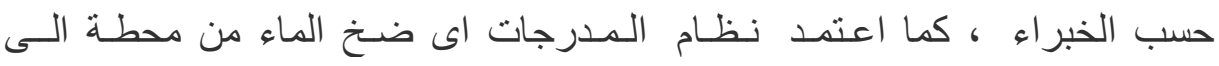

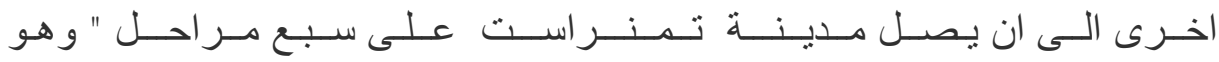

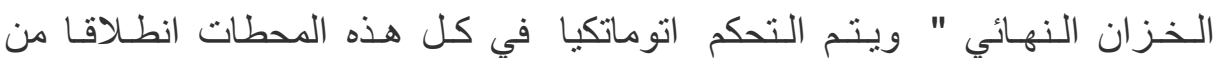
مركز التحكم بتمنر است. إن هذا الانجاز من شأنه ان يقضي نهائيا على مشكل الماء بالاهقار وهو

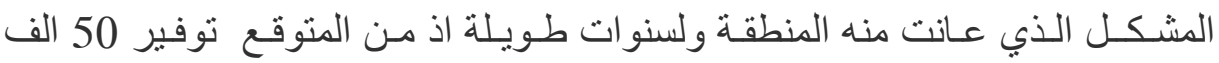
مـتر مكعب من المياه الصـالحة للشـرب إلى سنة 2050 بمعدل تـوزيع يومي يقدر 
بـ 250 متر مكعب ليصل مرحلته النهائية بـ 100 ألف متر مكعب. ويدخل تجسيد

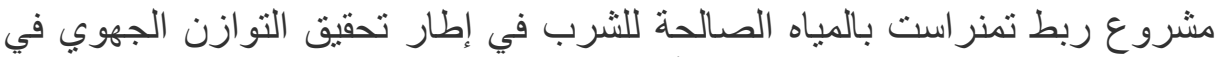

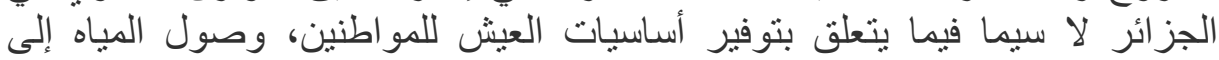

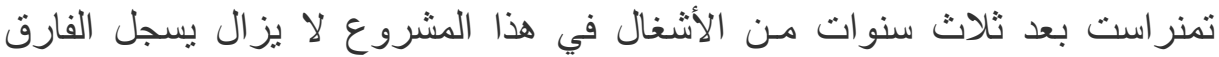

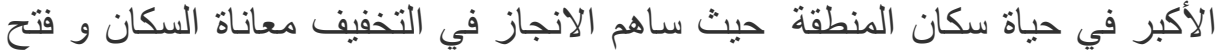

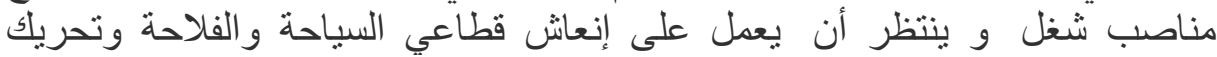

اقتصاد المنطقة.

ونم بالموازاة مع هذا المشروع الذي سمي بمشروع القرن تجديد شبكة توزيع

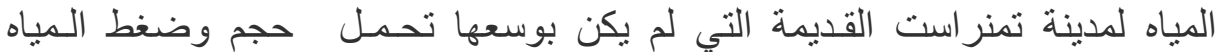

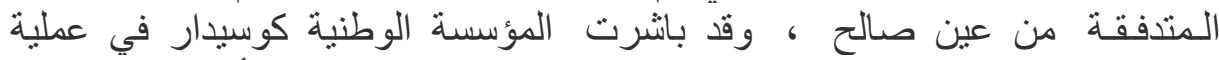

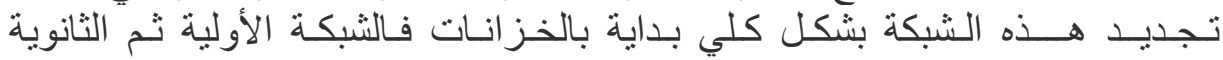

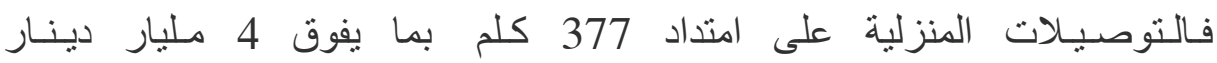

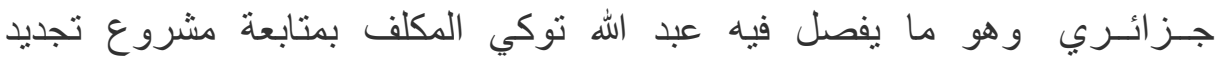

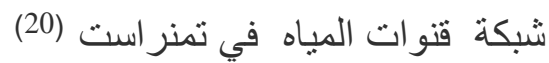
ج. قطاع الموارد المائية و السياحة:

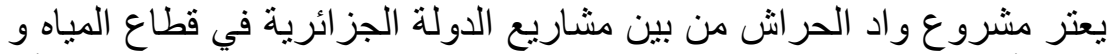

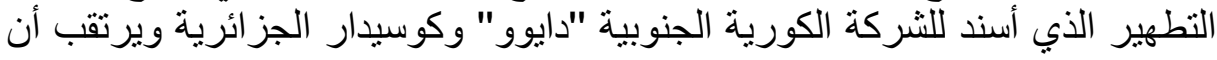
يكون جاهزا في 2016 ،ليتحول واد الحراش إلى معلم سياحي وطبيعي في قلب العاصمة. وهو يتضمن معالجة واد الحراش على مسافة 18 كلم إلى غاية مشارف حمام ملوان، وينتظر أن يتم إز الة التلوث وجعل الواد قابل للإبحار على مسافة 5 كلم،

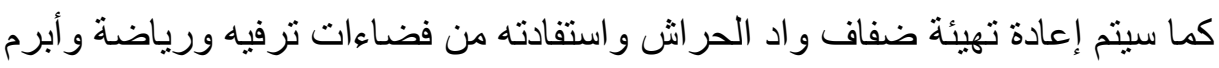

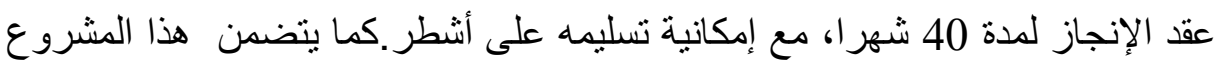

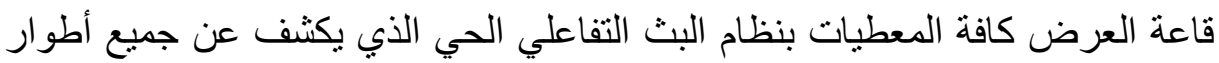

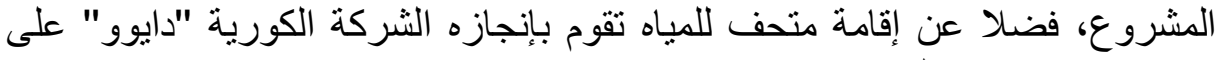

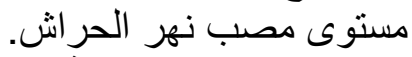

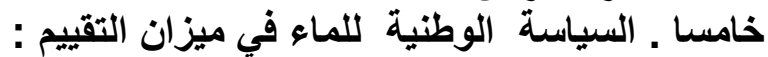

تعتبر الحكومة الجزائرية أن للماء جانبا اقتصاديا غيران الفير أنها تعتبر أيضا أن

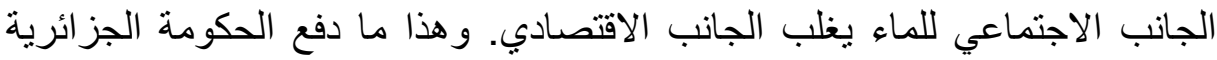

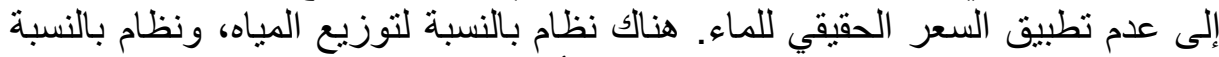

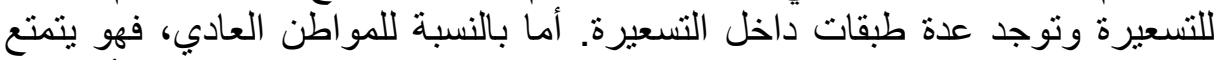

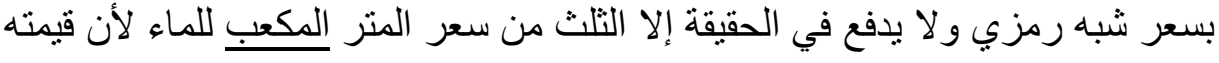

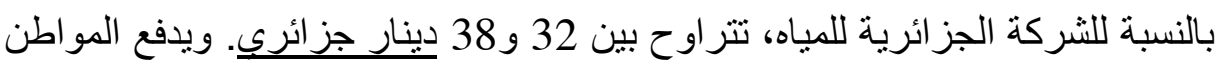
العادي قيمة 11 دينار جزائري فقط للمتر المكعب. بينما هناك تموين من طرف

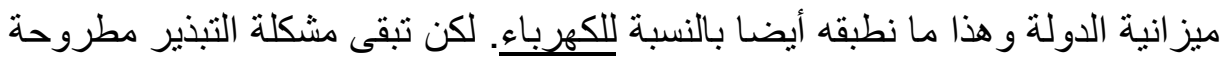

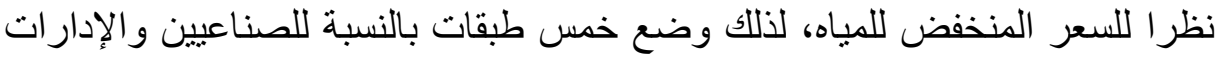

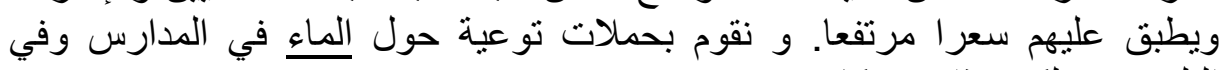
التلفزيون ولكن هذا غير كاف.

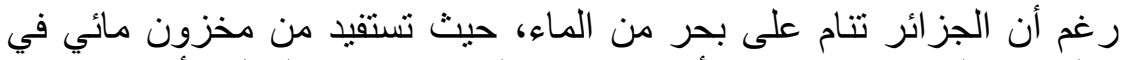

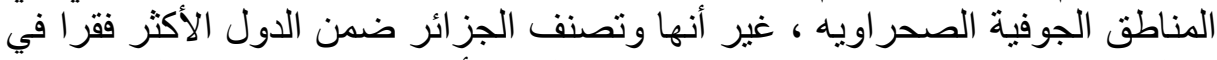
العالم من حيث الامكانيات حيث ترتب تحت الحد الأدنى النظري للندرة التهن التي يحددها 
البنك العالمي بـ 1000 م3 /فرد سنة حيث ان الراتب المائي النظري في الجزائر الذي كان في عام 62 يقدر بـ 1500 م3 /فرد سنة ، تر اجع عام 99 إلى 500م3 فرد فرد سنة.

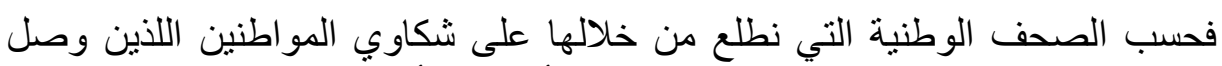

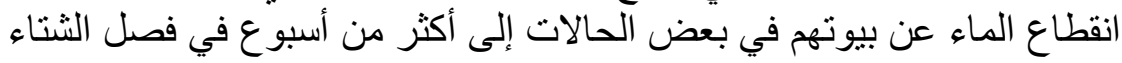

و يمكن تلخيص أهم السلبيات التي تعاني منها السياسية الجزائرية في هذا المجال إلى : - n

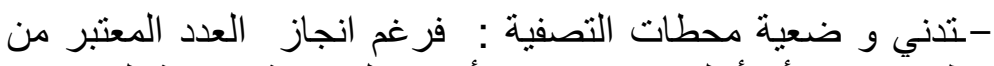

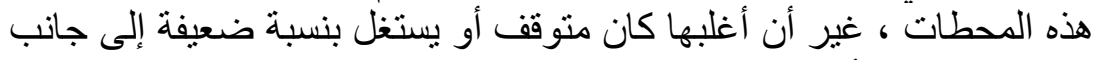

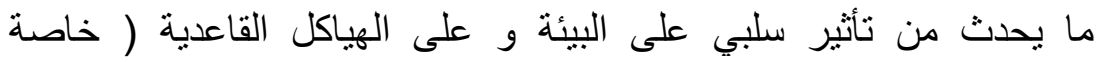
الطرقات و انز لاقات التربة.

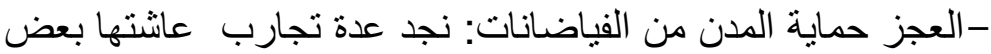

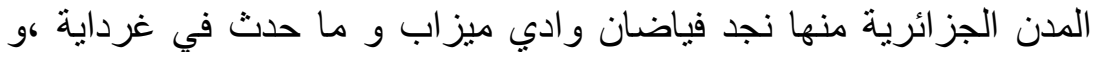

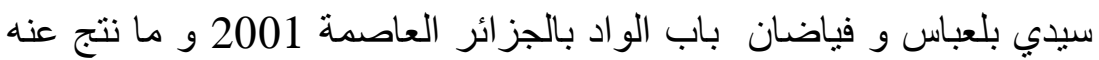
من خسائر مادية و بشرية

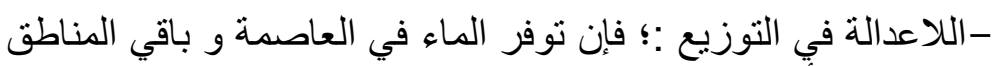

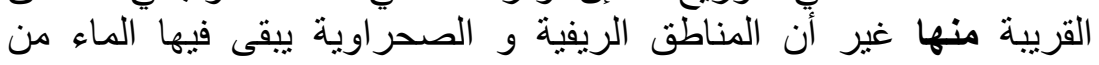

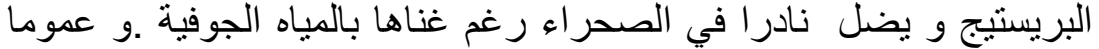

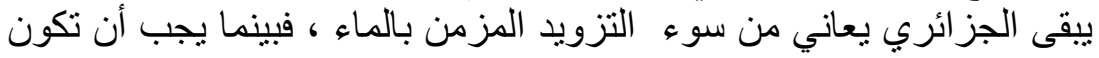

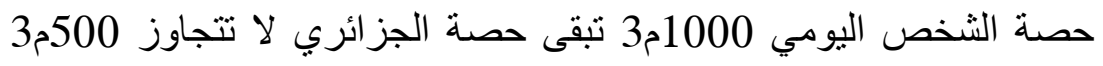
و عليه يصنف بعض الباحثين الجزائر ضمن الدول التي تعاني من ندرة في المياه

-رغم قدرات الجزائر في هذا المجال و التي تقدر بحوالي 15 مليار م3 و حوالي 31000 مليار م3 من المياه الجوفية الغير مستغلة تبقى الجزائر

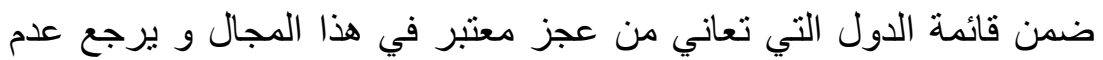

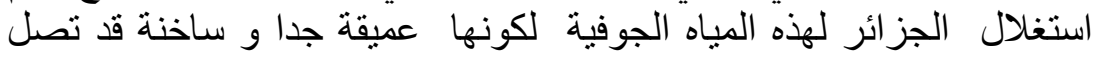
إلى حوالي 60 درجة ،و بالتالي فعملية استخر اجها مكلف جداء للأنها تتطلب وسائل تكنولوجيا هامة لاستخر اجها و تحويلها(21)

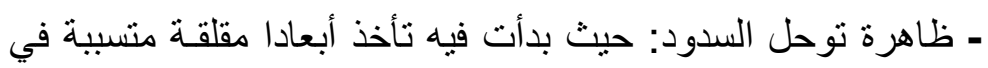
ضياع ما لا يقل عن 32 مليون متر مكعب من الماء كل سنة وهو ما يعادل سدا واحدا. وما زاد من هذه المشكلة عدم توفر البلاد على الكفاءة والخبرة

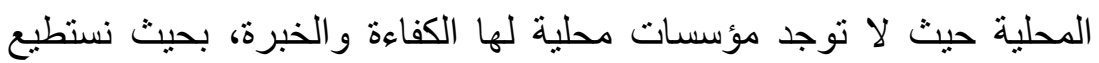

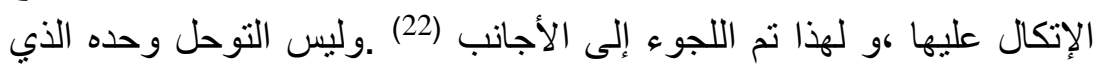

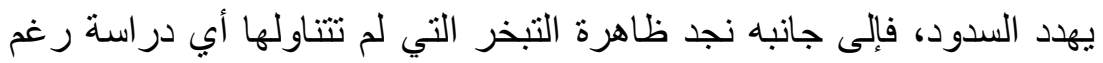
ضياع متوسط 250 مليون متر مكعب وهي كمية تكفي لمله سد كبير. و غير بعيد عن السد، على مستوى ضفاف حوض التخذية يتسرب مات ملتون مقداره

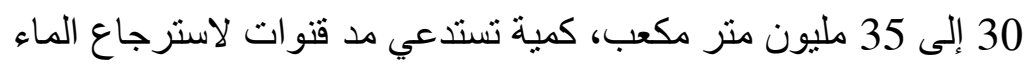




$$
\text { الضائع واستغلاله في الزراعة. }
$$

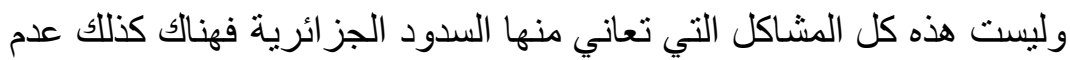

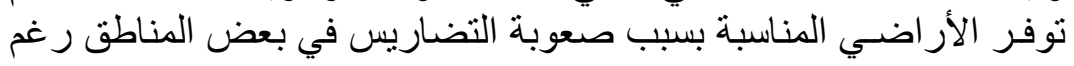

$$
\text { احتو اءها على شبكة مـن الوديان، تضيع دون استغلالها. }
$$

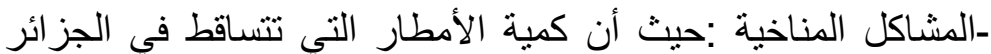

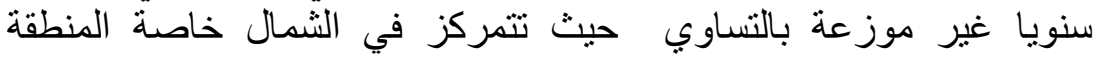
الساحلية التي تترواح كمية بين 80 إلى 100 م3 ، بلى بينما نجد منطقة الصحر اء الجافة تسجل نسبة قليلة جدا حوالي 20 م3 ، ، غير أن 67 مليار منها تتبخر حتى قبل أن تصل الأرض ، و5,2 مليار متر مكعب تموّن المياه الجوفية، و5,5 مليار متر مكعب تتسرب نحو البحر، ليبقى منها حوالي 5, 12 مليار متر مكعب.

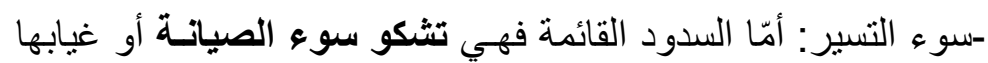

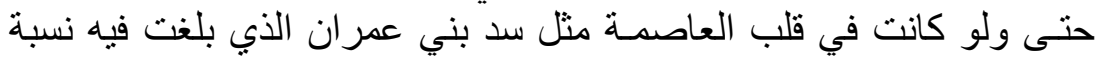
التوحل 60 \%بعدما تر اكمت وباتت تكلفة تصفيته باهظة. كما يظهر سوء التسيير كذلك من خلال عدم قدرة الوكالة الجزائرية للمياه لتغطية سوى 800

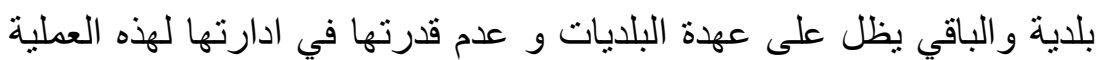

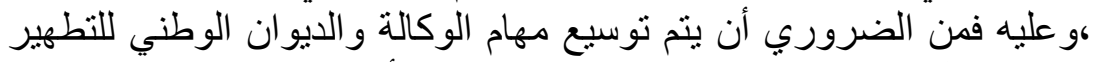
إلى باقي البلديات بالتدريج لضمان النئ خدمة عمومية أكثر فعالية.

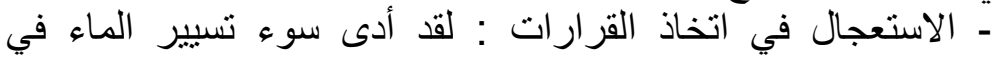

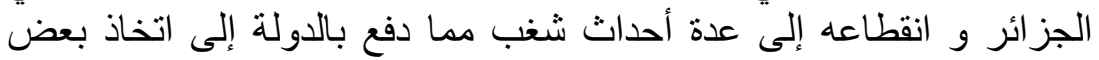

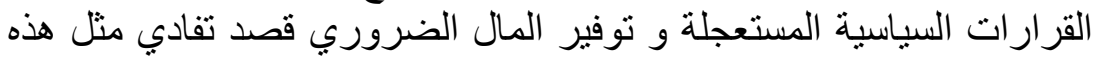

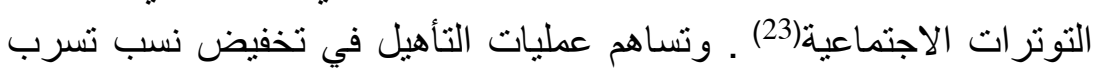
المياه التي تعود إلى قدم شبكات المياه في العديد من المناطق(24.

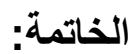

رغم ما تم التطرق له من امكانيات الجز ائر في ميدان المياه و السياسة المتبعة

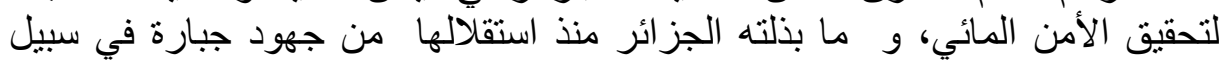

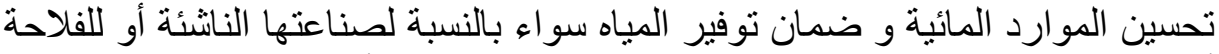

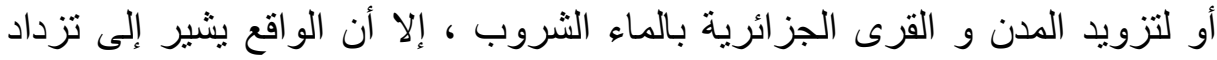

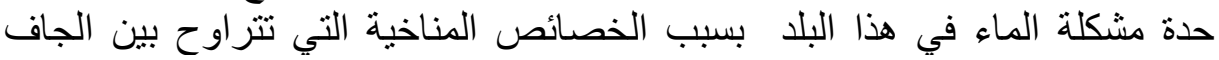

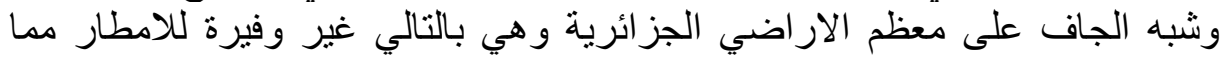

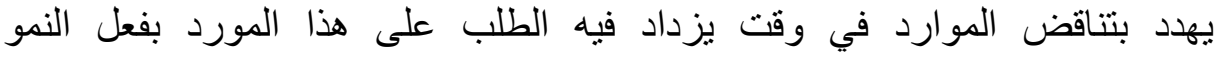

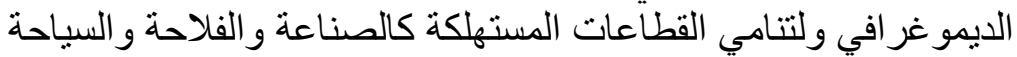

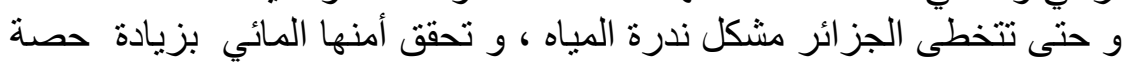

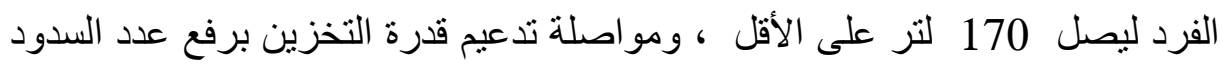

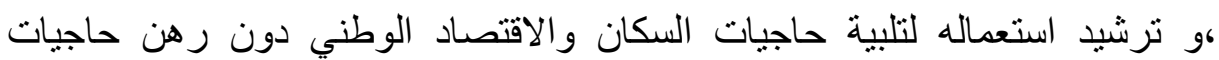

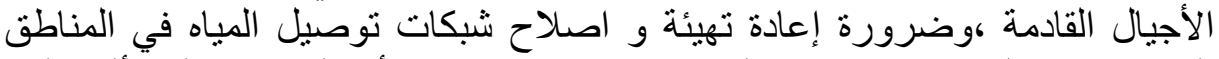

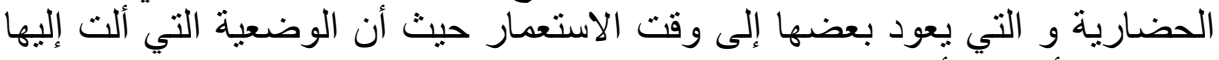

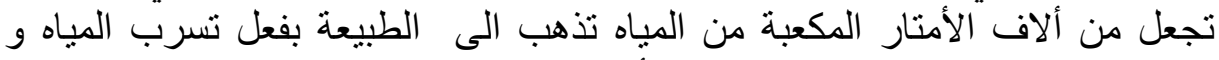

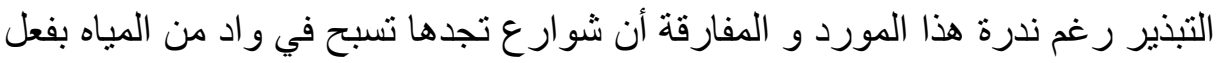


الوضعية التي ألت لها هذه القنوات حيث كانت 50\% من كمية المياه الصالحة

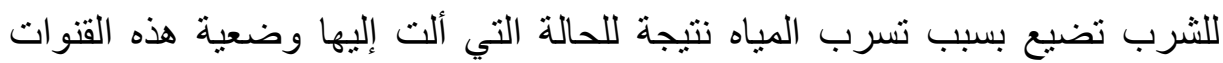

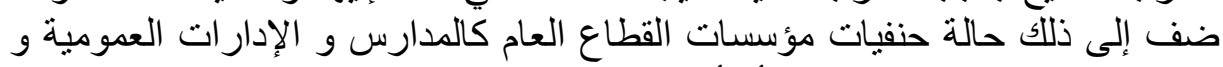

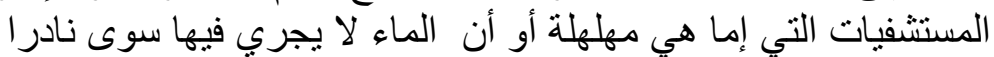

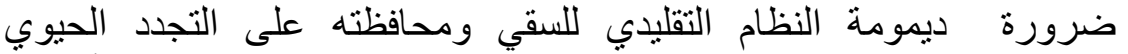

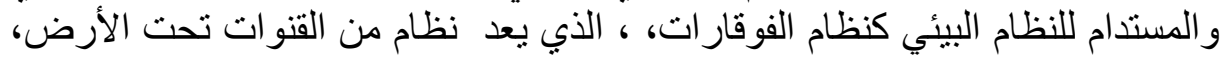

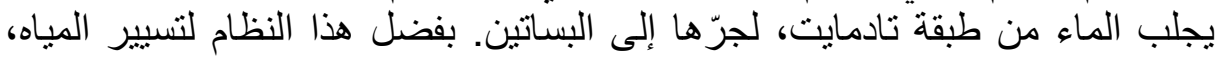

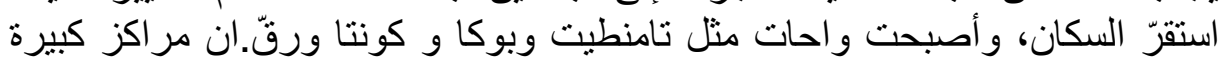

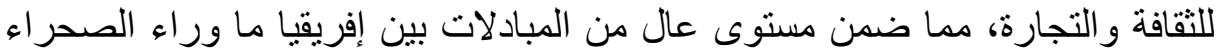

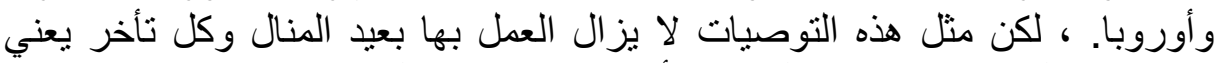

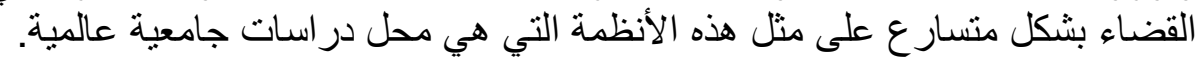

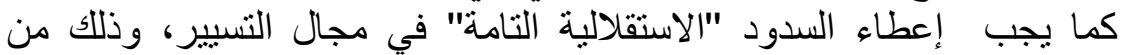

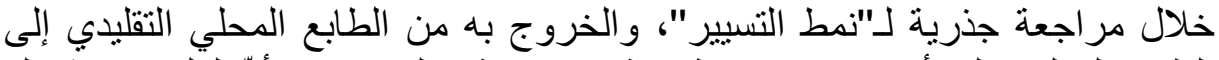

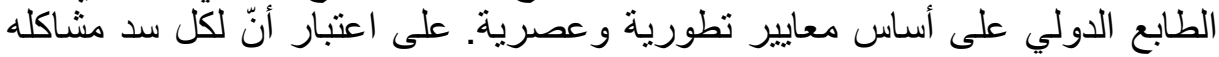

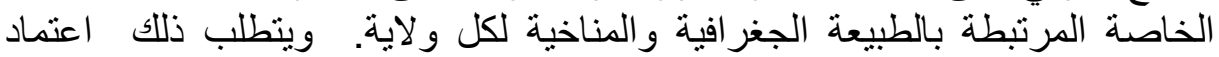

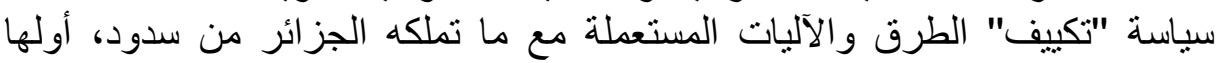

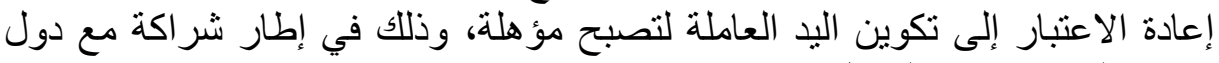
صديقة لها خبرة في المجال.

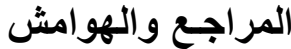

1. -UNEP. Water Security and Ecosystem Services : the Critical Connection.

Available

at: http://www.unep.org/themes/freshwater/pdf/the-critical-connection.pdf

2. -Wikipedia. Water Security. Available at :http :// www.en.m.wikipedia.org/wiki/water-security

3. http://www.siee-pollutec.com/nw/home/exposez/le-marche-de-l-eau.htm

4. OCDE. De l'eau pour tous, perspectives de l'OCDE sur la tarification et le financement..op-cit.p133-155

5. OCDE. De l'eau pour tous, perspectives de l'OCDE sur la tarification et le financement..op-cit.p133-155

6. -Ibid p .75-49

7. -Bouchrit Rouissal. » la gestion des Ressource en Eau an Algerie : Situation ,defis et apport de l'approche systémique » voir le site : http://fseg.univ tlemcen.dz/rev\%2010\%20en\%20pdf/ROUISSAT\%20Bouchrit.pdf

8. -OCDE. De l'eau pour tous, perspectives de l'OCDE sur la tarification et le financement. Voir site internet. Pp 21-22

9. -Djilali Sari. La crise Algérienne Economique et Sociale Diagnostic et

Perspectives. Paris: Publisud. 2001. P 12

10. من موقع الديوان الوطني للإحصاء//http:/wwww. ons. dz ttp://wwww. ons. dz .11

12. -تحلية ماء البحر : حل جلي لندرة الماء في الجزائر. ارجع للموقع : تحلية-ماء-البحر-

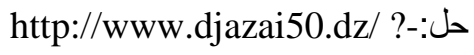


13. -Maghreb Emergent. »avec la méga Station de Dessalement d'El Maqtaa ,Oran devient excédentaire en Eau Potable . "voir le site : http://www.maghrebemergent.com/component/k2/item/24887-avec-lamega-station-de-dessalement-d-el-maqtaa-oran-devienr-excedentaire-eneau-potable.htm

$$
\text { 14. -جريدة الخبر ـ "الجز ائر تتام على بحر من الماء". الخميس } 14 \text { مارس } 2013
$$

15. -Boucheja Abdellah. La POLITIQUE Nationale de l'Eau En Algerie .voir le site : http://wwww.inbonews.org/IMG/pdf/6_BOUCHEDJA_istanbul_2012.pdf

16. UHA I UITTO AND ALFRED M DUDA. ."Management of transboundary water resources:

17. -lessons from international cooperation for conflict prevention". The Geographical Journal, Vol. 168, No., December 2002, pp. 365-378

18. 17-http://www.ennaharonline.com/ar/national/190151\%D9\%88\%D8\%B2\%D9\%8A\%D8\%B1-\%

19. -

18http://www.djazair50.dz/?\%D8\%AA\%D8\%AD\%D9\%84\%D9\%8A9 \%84\%D8\%A8\%D8\%AD\%D8\%B1-\%D8\%AD\%D9\%84

20. -http://www.radioalgerie.dz/ar/2010-04-29-13-30-51/2010-10-12-13-5734/26234-2013-11-07-06-23-46

21. Malgré d'importantes potentialités HydriquesM les Algeriens, des «Sous-alimentés» en eau voir le site : http://monjournaldz.com/fr/index-php/au-fil-de-l-actualité/3473-malgrédes-potentialités-hydriques-mobilisables-de-15-milliards-de-mètrescubeset-de-31-000-milliards-de-mètrs-cubes-d-eau-souterraine-nonexploitée-les-algériens,-des-«-sous-alimentées-« -en eau.html.

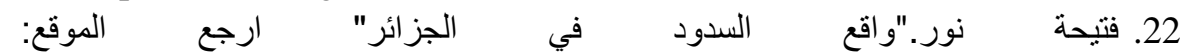
http://www. rachidia29.com/vb/showthread.php?t=98

23. Hydro plus ، مجلة المحترفين في ميدان الماء والصرف الصحي، عدد خاص مغرب

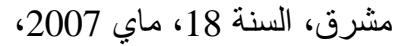

24. http://www.elkhabar.com/ar/autres/fotouressabah/326936.html\#sthash.L 3x0qxUg.dpuf 